\title{
Identificação dos cuidados à saúde prestados, pela equipe de enfermagem, aos idosos residentes em uma instituição de longa permanência filantrópica do município de São Paulo
}

\author{
Mirela Bertoli Passador
}

\begin{abstract}
Dissertação apresentada ao Programa de Pós-Graduação em Saúde Pública da Faculdade de Saúde Pública da Universidade de São Paulo para obtenção do título de Mestre em Saúde Pública
\end{abstract}

Área de concentração: Serviços de Saúde Pública.

Orientadora: Prof $\mathrm{Dr}$ Helena Akemi Wada Watanabe 
À minha família pela paciência e compreensão de minhas ausências. Em especial à minha irmã Alessandra, que em momento delicado e decisivo de sua vida, nunca deixou de me apoiar. 


\section{Agradecimentos}

As dificuldades foram inúmeras, mas mediante a contribuição e apoio de diversas pessoas, foram superadas. A todas aquelas que acreditaram e tornaram possível a realização deste trabalho, a minha imensa gratidão.

A Profa ${ }^{-}$Dra Helena Akemi Wada Watanabe, não só pela orientação, mas pelo carinho e cuja confiança em mim depositada se mostrou inabalável mesmo nos momentos mais difíceis da caminhada.

A Profa Dra ${ }^{\text {a }}$ Rita de Cássia Chamma pela disponibilidade, agilidade e imenso carinho e paciência.

Aos amigos do Conselho Regional de Enfermagem de São Paulo, principalmente as Sras. Cleide Mazuela Canavezi, Maria Angélica Azevedo Rosin e Sr. Cláudio Alves Porto, pelo apoio incondicional e respeito as minhas ausências.

As amigas queridas que nunca me abandonaram, Flávia Zulzke e Fabrícia Cristina Giancole Góes, mesmo na minha falta de tempo para atendê-las.

A minha irmã Bruna que soube compreender a minha presença ausente durante a escrita deste trabalho 


\section{ALEGORIA DE HIGINO}

"Certa vez, atravessando um rio, Cuidado viu um pedaço de terra argilosa: cogitando, tomou um pedaço e começou a lhe dar forma. Enquanto refletia sobre o que criaria, interveio Júpiter. O Cuidado pediu-Ihe que desse espírito à forma de argila, o que ele fez de bom grado. Como cuidado quis então dar seu nome ao que tinha dado forma, Júpiter proibiu e exigiu que fosse dado seu nome. Enquanto Cuidado e Júpiter disputavam sobre o nome, surgiu também a terra (tellus) querendo dar o seu nome, uma vez que havia fornecido um pedaço de seu corpo. Os disputantes tomaram Saturno como árbitro. Saturno pronunciou a seguinte decisão, aparentemente aquitativa: "Tu, Júpiter, por teres dado o espírito, deves receber na morte o espírito e tu, terra, por teres dado o corpo, deves receber o corpo. Como porém foi o Cuidado quem primeiro o formou, ele deve pertencer ao Cuidado enquanto viver. Como, no entanto, sobre o nome há disputa, ele deve se chamar 'homo', pois foi feito de húmus (terra)". 


\section{RESUMO}

PASSADOR. M.B. Identificação dos cuidados à saúde prestados, pela equipe de enfermagem, aos idosos residentes em uma instituição de longa permanência filantrópica do município de São Paulo [dissertação de mestrado]. São Paulo: Faculdade de Saúde Pública da USP; 2008.

Introdução - Atualmente não se sabe quantos e de que forma idosos residem em instituições de longa permanência em nosso país. O poder público considera estas instituições como instrumentos de atenção social e não de saúde e, assim, não há obrigatoriedade da manutenção de profissionais da área da saúde nestes locais. Entretanto, através da atuação profissional, em visitas a, aproximadamente, quatrocentas instituições de longa permanência para idosos, sempre foi encontrado um profissional auxiliar de enfermagem prestando cuidados aos idosos residentes. Objetivo - Conhecer o significado atribuído por auxiliares de enfermagem que trabalham em uma instituição de longa permanência ao termo cuidados à saúde e sua relação com as atividades por eles desenvolvidas. Método Pesquisa qualitativa, de caráter exploratório. A coleta de dados se deu por meio de grupo focal, cujos temas para discussão se basearam em três questões sobre as atividades desenvolvidas e a definição de cuidados à saúde. Também foi utilizado como instrumento de coleta de dados, um questionário estruturado, contendo oito questões relativas à caracterização 
da população. A população foi constituída por treze auxiliares de enfermagem que prestam serviço em uma instituição de longa permanência para idosos. Os dados foram analisados qualitativamente utilizando-se a "Análise de Conteúdo". Resultados - Os sujeitos conceituam cuidados à saúde, bem como descrevem os cuidados à saúde prestados como a realização de procedimentos técnicos direcionados à satisfação das atividades básicas de via diária. Um número pequeno de profissionais citou atividades de apoio emocional e de lazer como sendo cuidados à saúde. Conclusão - Os auxiliares de enfermagem conceituam cuidados à saúde a partir de sua experiência de formação e de trabalho, centrada na realização de procedimentos técnicos. Cuidados psicossociais são referidos por poucos profissionais, mormente os mais velhos e com mais tempo de trabalho na instituição.

Descritores: cuidados a saúde, saúde do idoso, envelhecimento. 


\section{ABSTRACT}

Passador. M.B. Identification of the health care given by the nursing team to elderly residents of filantropic institutions of long permanence in the city of São Paulo, [dissertation of masters degree]. São Paulo: Faculdade de Saúde Pública da USP; 2008.

Introduction - At the present time there is no information about how many people are living in long term care permanence institutions in Brazil, nor how do they live in these institutions. Brazilian government considers these institutions as instruments of social attention, not of health responsibility and, thus, there is no obligation of maintaining health professionals in these facilities. However, through professional experiences, during visits to, approximately, four hundred long permanence institutions for senior citizens, there was always a licensed professional nurse assisting the elderly residents. Objectives- - Identify the meaning of the term "health care" for the licensed nurses who work at an elderly long term care institution and what kind of health cares is being given by them at the institution Method Qualitative research, with exploratory matter. The collection of data was presented by focal groups, in which the themes for discussion were based on three questions about the activities developed and the definition of health care. A structured questionnaire was also used as a data collection instrument, containing eight questions related to population identification. The population was constituted by three Lincesed Professional Nurses who work 
at a long permanence institution for senior citizens. The data were analyzed qualitatively using the "content analysis" Results - The subjects have the concept that health care, such as they describe the health care offered, as the completion of technical procedures directed to the satisfaction of the basic daily life activities. A small number of professional cited activities as emotional support and leisure as health care. Conclusion - The nurse aid appraises health care from its own experience of formation and work, centered in the accomplishment of procedures techniques. Psychosocial care is related by few professionals, mainly older and with more time of work in the institution.

Key words: health care, health of the elder, aging 


\section{ÍNDICE}

APRESENTAÇÃO 12

1 INTRODUÇÃO

1.1 INSTITUIÇÃO DE LONGA PERMANÊNCIA PARA IDOSOS (ILPI) 22 NO BRAISL

1.2 SAÚDE E CUIDADO A SAÚDE 28

1.3 CUIDADO A SAÚDE DO IDOSO 33

2 OBJETIVOS 38

3 MÉTODOS 39

3.1 TIPO DE ESTUDO 39

3.1.1 ESTUDO PRELIMINAR 40

3.2 CAMPO E POPULAÇÃO 41

3.3 COLETA DE DADOS 45

3.4 REFERENCIAL METODOLÓGICO 48

3.5 ASPECTOS ÉTICOS DA PESQUISA 49

4 RESULTADOS E DISCUSSÕES 51

4.1 CARACTERIZAÇÃO DA EQUIPE DE ENFERMAGEM 54

4.2 REPRESENTAÇÕES SOBRE SAÚDE E CUIDADOS A SAÚDE EXPRESSAS PELOS PROFISSIONAIS DE ENFERMAGEM 59

4.2.1 Definição de Cuidados à Saúde $\quad 60$

4.2.2 Cuidados à Saúde Desenvolvidos pelos Auxiliares de Enfermagem

5 CONCLUSÃO 72

6 CONSIDERAÇÕES FINAIS 73 
ANEXOS

$\begin{array}{ll}\text { Anexo } 1 \text { - Questionário } & 90\end{array}$

$\begin{array}{ll}\text { Anexo } 2 \text { - Termo de compromisso da pesquisadora } & 91\end{array}$

Anexo 3 - Termo de compromisso da instituição 92

Anexo 4 - Termo de consentimento livre e esclarecido 93

Anexo 5 - Ofício do COEP autorizando a realização da pesquisa 96

Anexo 6 - Primeira folha do currículo Lattes da Prof $^{a} \operatorname{Dr}^{\underline{a}}$ Helena Akemi Wada Watanabe

Anexo 7 - Primeira folha do currículo Lattes da Enfa ${ }^{-}$Mirela Bertoli Passador 


\section{Lista de Quadros}

Quadro 1 - Caracterização dos auxiliares de enfermagem, que trabalham em uma instituição de longa permanência para idosos (ILPI), segundo idade, sexo, tempo de formação profissional, tempo de atuação na instituição, período de trabalho, demais vínculos profissionais e experiência profissional anterior, São Paulo, março de 2008.

Quadro 2 - Conceitos de cuidados à saúde dados pelos auxiliares de enfermagem que trabalham em uma instituição de longa permanência para idosos, São Paulo, março de 2008

Quadro 3 - Atividades de cuidados à saúde relatadas como desenvolvidas pelos auxiliares de enfermagem que trabalham em uma instituição de longa permanência para idosos, São Paulo, março de 2008. 


\section{APRESENTAÇÃO}

O envelhecimento populacional é um fenômeno mundial, conseqüente à diminuição das taxas de mortalidade e fecundidade. Em países desenvolvidos, a transição de um país jovem para um país envelhecido ocorreu de forma gradativa, o aumento da expectativa de vida refletiu a melhoria nas condições de vida da população. O contrário se deu em países em desenvolvimento, onde a população envelheceu pobre e teve, como principal genitora, a tecnologia (vacinas, antibióticos, métodos contraceptivos), o que é considerado um processo de envelhecimento artificial.

Este envelhecimento populacional tem significativo impacto no desenvolvimento das sociedades, assim como, também, no bem estar não só dos idosos como da população mais jovem. As principais dimensões afetadas são as condições de saúde dos idosos, a participação no contingente de mão-de-obra, as características das famílias e os sistemas de pensões e aposentadorias.

No Brasil não foi diferente. O rápido envelhecimento da população, ocorrido nas últimas décadas, transformou a visão que se tinha do país, e deixou-se de vê-lo como país jovem. Atualmente, os brasileiros com mais de sessenta anos representam $9,8 \%$ da população.

Juntamente com a transição demográfica, mudanças sociais e econômicas, como a industrialização, o aumento da população urbana e principalmente, a ascensão da mulher ao mercado de trabalho, contribuíram 
para a alteração da conformação da família. A mulher que, culturalmente, assume a responsabilidade pelos cuidados com os mais velhos, encontra grandes dificuldades em manter este papel. Além disso, a ocorrência de seqüelas de doença e agravos não transmissíveis complica, e muito, a tarefa de cuidar do idoso.

Inicialmente, a instituição de longa permanência para idosos, conhecida habitualmente por asilo, surgiu como abrigo para os idosos de baixa renda, que moram sós e com suporte familiar precário. Atualmente, esta visão se expandiu. Este tipo de instituição torna-se uma opção em casos de necessidade de reabilitação intensa, de necessidade de cuidado intensos no período entre a alta hospitalar e o retorno ao domicílio, de pessoas em estágios terminais de doenças, ou com níveis elevados de dependência e na ausência temporária de cuidadores domiciliares.

Não se sabe quantos idosos se encontram institucionalizados em regime de longa permanência no Brasil, pois não há implantação efetiva, em todo território nacional, de ações de regulamentação e fiscalização das atividades desenvolvidas por este tipo de instituição.

Assim, vê-se uma mobilização no sentido de mapear o quantitativo e a localidade destas instituições, além das condições de vida e saúde de idosos institucionalizados para que estratégias de atendimento e intervenções adequadas sejam propostas.

O presente estudo pretende contribuir com este universo investigativo, através da análise do conceito de cuidado à saúde referido por profissionais de enfermagem que atuam em uma instituição filantrópica de 
longa permanência para idosos. Está dividido, didaticamente, em sete seções, a fim de facilitar a compreensão do tema.

A primeira seção abriga a introdução onde se faz a explanação dos motivos que levaram a pesquisadora a abordar o tema, bem como uma revisão bibliográfica sobre as instituições de longa permanência para idosos no Brasil, os conceitos de saúde e cuidado à saúde e cuidado à saúde do idoso.

O objetivo do estudo foi descritos na seção dois, e está focado no conceito de cuidado à saúde e nas atividades relacionadas aos cuidados à saúde desenvolvidas pelos profissionais de enfermagem, através de sua percepção.

O método utilizado para a análise do material pesquisado é apresentado na terceira seção, com informações sobre o tipo de estudo, o estudo preliminar, o campo e a população, a coleta de dados, o tratamento dos dados e os aspectos éticos da pesquisa.

Na seção intitulada resultados e discussões, os dados levantados são apresentados em forma de quadros e analisados sob a ótica de diferentes referenciais teóricos, sendo esta a seção de número quatro.

A conclusão, descrita na seção cinco, revela os achados do estudo, e a seção de número seis expressa as percepções e o posicionamento da autora frente as questões discorridas.

$\mathrm{Na}$ última seção, são apresentadas as referências utilizadas para construção do estudo, de acordo com o modelo da Associação Brasileira de Normas Técnicas (ANBT). 


\section{INTRODUÇÃO}

O presente estudo surgiu do interesse despertado acerca do funcionamento das instituições de longa permanência para idosos.

Enquanto enfermeira, ocupando o cargo de Coordenadora do Departamento de Fiscalização do Conselho Regional de Enfermagem de São Paulo (COREN-SP) - Matriz, a pesquisadora direcionou suas atividades, principalmente para a fiscalização das ações de enfermagem desenvolvidas junto aos idosos institucionalizados, em regime de longa permanência. No transcorrer destas atividades, recebeu convite para, em nome do CORENSP, participar das reuniões do Fórum de Instituições de Longa Permanência para Idosos (ILPIs), composto por diversas instituições do Estado de São Paulo, principalmente, as filantrópicas.

Este Fórum tem por objetivo a troca de experiências entre os diversos profissionais que prestam cuidados aos idosos institucionalizados, tendo como finalidade principal a melhoria na qualidade do atendimento prestado e, conseqüentemente, a melhoria na qualidade de vida dos idosos residentes nestas instituições.

É interessante informar que o Fórum, apesar de não ser legalmente constituído, é reconhecido em algumas instâncias municipais e tem participado como uma das representantes das ILPI em discussões que envolvam o assunto institucionalização e idosos institucionalizados.

Cabe informar que compete ao Conselho Regional de Enfermagem 
de São Paulo, entre outras atribuições, a disciplina e fiscalização do exercício profissional dos seguintes profissionais: enfermeiros, obstetrizes, técnicos e auxiliares de enfermagem, observadas as diretrizes gerais do Conselho Federal de Enfermagem; a manutenção do registro dos profissionais com exercício no estado de São Paulo; o conhecimento e a decisão sobre assuntos atinentes à ética profissional, impondo penalidades cabíveis e o zelo pelo bom conceito da profissão e dos que a exercem.

O convite para participação no Fórum de Instituições de Longa Permanência para Idosos se deu porque o Conselho Regional de Enfermagem de São Paulo, através de suas visitas fiscalizatórias, objetivando verificar as ações desenvolvidas pelos profissionais de enfermagem que lá atuavam, solicitava uma séria de adequações, visando o cumprimento da Lei $\mathrm{n}^{0}$ 7.498/86 que regulamenta a profissão de enfermagem. Nos casos em que as adequações não eram cumpridas, ou em que se observavam outros problemas, ocorria a comunicação a outros órgãos de fiscalização profissional, como os Conselhos Regionais de Medicina e de Farmácia, a vigilância sanitária, bem como autoridades policias, através da realização de boletins de ocorrência e ofícios ao Ministério Público do Estado de São Paulo.

A partir da participação neste Fórum, a relação entre o Conselho Regional de Enfermagem do Estado de São Paulo e os trabalhadores e proprietários de instituições de longa permanência para idosos se fundamentou em conhecimento mútuo do funcionamento e das finalidades de ambas as instituições, o que gerou uma parceria que perdura até os dias 
atuais.

Através da busca por conhecimentos sobre os cuidados à saúde prestados, pelos profissionais de enfermagem aos idosos institucionalizados em regime de longa permanência, percebeu-se que a literatura não apresenta estudos suficientes sobre este assunto através de busca nas bases de dados LILACS, MEDLANE, BDENF e ScIELO. Quando se aborda a institucionalização do idoso, os trabalhos têm centrado o enfoque nos idosos que lá residem, através da caracterização de sua dependência, condição sócioeconômica ou visão de asilamento, ou na instituição, no que diz respeito à sua estrutura administrativa, funcional e de recursos humanos. Localizou-se alguns estudos direcionados à equipe de funcionários que prestam cuidados diretos aos idosos, porém, sem diferenciá-los quanto às suas profissões.

Sabe-se que o envelhecimento da população brasileira ocorreu de forma rápida. Com referência a dados percentuais, a proporção de idosos na população brasileira evoluiu de um total de 7,3\% no ano de 1991 para 8,6\% em 2000 (IBGE, 2002). Estimativas para 2025 indicam que se terá 32 milhões de idosos no país, isto é, 14\% da população total (OPAS, 1998a). Desta forma, conforme definição da Organização Mundial da Saúde, o Brasil é um país envelhecido desde o final do século passado, pois um país envelhecido é aquele onde a proporção de idosos ultrapassa $7 \%$ da sua população (OPAS, 1988b).

No Brasil, um país em desenvolvimento, considera-se como pessoa idosa aquela que apresenta idade igual ou superior a 60 anos (BRASIL, 
2003).

Sabe-se que o envelhecimento não é sinônimo de impotência, dependência, incapacidade ou doença, porém, em nosso país, que ainda vive com o desafio de controlar as doenças transmissíveis, a mortalidade infantil, as desigualdades sociais e regionais, os idosos não encontram respaldo no sistema público de saúde, tendo, muitas vezes, que conviver com seqüelas de doenças que causam incapacidades e perda de autonomia (CHAIMOWICZ, 1997).

A perda de habilidades pelos idosos tende a seguir uma hierarquia. Primeiro, ele perde a capacidade de realizar atividades instrumentais de vida diária como cozinhar, controlar seu próprio dinheiro e após perde a capacidade de realizar atividades básicas de vida diária como banhar-se e alimentar-se (DUARTE e LEBRÃO, 2006).

RAMOS et al. (1993), em sua pesquisa sobre idosos residentes na área metropolitana de São Paulo, informam que 53\% necessitavam de ajuda, parcial ou total, para realizar uma atividade de vida diária, enquanto $29 \%$ necessitavam de ajuda, parcial ou total, para realizar até três atividades, e $17 \%$ para realizar quatro ou mais atividades. Também verificaram que, com o passar da idade, esse estado vai se agravando. Dos 65 aos 69 anos 54\% dos idosos não necessitavam de auxílio para realizar nenhuma atividade, enquanto este percentual, a partir dos 80 anos, ficava em $15 \%$, sendo que destes, $28 \%$ tinham necessidade de cuidados em tempo integral. Este estudo abordou as atividades básicas e as instrumentais de vida diária. 
O estudo SABE, realizado no município de São Paulo no ano de 2000, abrangendo indivíduos com idade igual ou superior a 60 anos, residentes na região urbana, identificou que $26,6 \%$ dos idosos possuem dificuldades para realizar atividades instrumentais de vida diária, enquanto 19,2\% deles apresentam limitações para realizar atividades básicas de vida diária. Com o avançar da idade, percebe-se um aumento de limitações funcionais. Isto é confirmando através da análise dos dados estratificados segundo a idade, ou seja, dos idosos que apresentam dificuldades para desenvolver três ou mais atividades básicas de vida diária, 47,9\% tinham idade entre 60 e 74 anos, aumentando para 52,1\% para aqueles com 75 anos ou mais (DUARTE, 2003).

Em instituições de longa permanência para idosos, conforme estudo desenvolvido no município de Caxias do Sul, CORTELLETTI e col. (2004), detectaram, através da entrevista com os idosos residentes em instituições de longa permanência cuja média de idade era de 78 anos e meio, que $54,7 \%$ necessitavam de auxílio para tomar seus remédios, 53,3\% necessitavam de auxílio para realizar atividades de higiene, 40,0\% necessitavam de auxílio para deambulação e 21,3\% necessitavam de auxílio para se alimentar. Verificaram também que grande parte dos idosos institucionalizados necessita de auxílio para desenvolver duas ou mais atividades de vida diária.

Atualmente, não se tem um número exato de quantos idosos residem em instituições de longa permanência no Brasil. Estima-se que este número seja cerca de 107 mil, ou seja, 1\% do total da população de idosos do país 
(CAMARANO, 2005 et al.).

Várias são as razões que levam à institucionalização do idoso. Estudos, como o de PAVARINI (1996) relatam, como predominantes, as relacionadas ao caráter socioeconômico (abandono e rejeição da família, falta de recursos humanos para o cuidado e precariedade de condições financeiras), mas não são descartadas as de caráter de saúde (seqüelas de doenças crônico-degenerativas - físicas e cognitivas). Assim, estas instituições podem desenvolver duas atividades distintas, as de atendimentos às necessidades sociais e as de atendimento às necessidades de saúde do idoso.

Cabe colocar que a institucionalização de idosos em regime de longa permanência é um tema pouco abordado pelo poder público. As políticas públicas são direcionadas a idosos que residem sozinhos ou com suas famílias (BRASIL, 1994; MINISTÉRIO DA SAÚDE, 2006a). Até o momento, não se tem uma política pública voltada, unicamente, para os idosos residentes em instituições de longa permanência

A Política Nacional do Idoso, disposta na Lei nº 8.842, informa que cabe aos órgãos e entidades públicas a adoção e aplicação de normas de funcionamento para instituições geriátricas e similares (BRASIL, 1994).

Diante de tal determinação, a Agência Nacional de Vigilância Sanitária aprovou um regulamento técnico que define normas de funcionamento para instituições de longa permanência para idoso de caráter residencial. Esta norma, ao abordar a questão de recursos humanos em seu item sobre cuidados aos residentes, determina a quantidade de cuidadores que deverá 
ser disponibilizada para atendê-los, de acordo com seu grau de dependência. Em nenhum momento, é citada a qualificação que estes cuidadores devem possuir, informando apenas, em outro item, que a instituição que possuir profissionais de saúde vinculados a sua equipe de trabalho deverá exigir que o mesmo mantenha registro ativo em seu conselho de classe (ANVISA, 2005).

As legislações que abordam o funcionamento de instituições de longa permanência para idosos refletem a visão do poder público, que as considera como equipamento social e não de saúde. Caso haja necessidade de algum tipo de atendimento à saúde, os idosos deverão ser atendidos através do Sistema Único de Saúde - SUS (MINISTÉRIO DA SAÚDE, 2006a), desta forma, instituições de longa permanência para idosos não necessitam ter, obrigatoriamente, em seu quadro de pessoal, profissionais da área da saúde.

Através da experiência profissional, enquanto fiscal do Conselho Regional de Enfermagem de São Paulo - COREN-SP e tendo visitado cerca de quatrocentas instituições de longa permanência para idosos, em todo o Estado de São Paulo, entre os anos de 1999 e 2007, verificou-se a permanência de vários idosos com necessidades de cuidados de saúde constantes nessas instituições e, com raríssimas exceções, têm-se encontrado pelo menos um auxiliar de enfermagem desenvolvendo suas atividades profissionais nessas instituições.

Pelo motivo acima exposto e por ser a Enfermagem uma profissão cuja essência e especificidade é o cuidado ao ser humano, seja de forma 
individual ou coletiva, representando o maior contingente de força de trabalho em cuidados à saúde, além de ser o grupo que assume mais funções e responsabilidades, conforme afirmam ROCHA e ALMEIDA (2000), MORAES e DUARTE (2002) e SÁ e FERREIRA (2004), os profissionais que compõem esse grupo foram escolhidos como sujeitos deste estudo.

Desta forma, o presente estudo pretende identificar quais são as atividades de cuidados à saúde, desenvolvidas por profissionais de enfermagem, a idosos residentes em instituição de longa permanência para idosos. Também visa contribuir para a reflexão sobre que tipos de cuidados à saúde estão sendo oferecidos a esta população e fomentar a realização de estudos direcionados a este tema, com intuito de contribuir para melhoria da qualidade de vida destes idosos.

\subsection{INSTITUIÇÃO DE LONGA PERMANÊNCIA PARA IDOSOS (ILPI) NO BRASIL}

A palavra instituição deriva do latim insittutione, que significa regra, norma, instituição ou estabelecimento de coisas (LOUZÃ NETO et al., 1986).

O surgimento de instituições para idosos fundamentou-se na caridade e num atendimento básico às necessidades de vida, como ter onde se alimentar, se banhar e dormir, sendo esta forma de assistência predominante por algumas décadas. Este tipo de instituição consagrou-se com o título de 
asilo, um reflexo da pobreza do indivíduo idoso e de sua família (PAVARINI, 1996).

A palavra asilo deriva do grego asylon, que significa o local onde as pessoas sentem-se abrigadas e protegidas contra diversos danos de qualquer natureza (REZENDE, 2002).

Para GOFFMAN (2005), os asilos são classificados entre os cinco tipos de instituições totais, sendo eles, juntamente com os abrigos para cegos, órfãos e indigentes, criados para cuidar de pessoas consideradas incapazes e inofensivas.

Segundo BAHURY (1996), as instituições totais têm esta denominação, pois encerram em si todas as esferas de vida: o trabalho, o repouso e o lazer. São organizações sociais dicotomizadas em comunidade residencial e organização formal.

Desta forma, toda a vida se processa num mesmo lugar e sob as mesmas regras. Qualquer que seja a atividade desenvolvida por um indivíduo, ele é acompanhado por outras pessoas, que são tratadas da mesma maneira e incentivadas a realizar, juntas, as mesmas coisas. Assim, as pessoas são forçadas a viver constantemente no coletivo, são obrigadas a submeter suas vidas a um conjunto de normas e rotinas que lhes são impostas pela instituição (GOFFMAN, 2005).

O estabelecimento destas normas e rotinas propicia a homogeneização do tratamento aos indivíduos residentes, não havendo espaço para diferenciações.

Com isso, torna-se mais fácil o controle sobre os indivíduos, pois 
todos devem respeito aos horários e calendário estipulados, estabelecidos de acordo com as necessidades e interesses da instituição, o que facilita, em muito, o trabalho da equipe de cuidados, pois esta organiza e planeja o que deve ser realizado (BAHURY, 1996).

Este pensamento é compartilhado por LOUZÃ NETO et al. (1986), que afirmam que, nestas instituições, a essência fundamental do ser humano, a individualidade, é usurpada dos indivíduos, pois todas as atividades de vida diária são executadas em um mesmo local, sempre com a presença de outros indivíduos e subordinada a uma autoridade única, a das normas e rotinas da instituição.

Com estas atitudes, segundo PAVARINI (1996), o ambiente institucional estimula o conformismo e a dependência comportamental, pois as atividades devem ser realizadas em um ritmo imposto pela instituição, sendo que o profissional não dispõe de tempo para interagir com o idoso, predominando a prática de "fazer por eles", mesmo quando eles podem responder por si.

O Censo Demográfico Brasileiro de 2000 indica a existência de 113 mil idosos vivendo em residências coletivas. Porém, considera como residência coletiva conventos, presídios, hotéis, não especificando o número preciso de idosos que residem em instituições de longa permanência (CAMARANO, 2005).

O número de idosos institucionalizados aumenta nas idades mais avançadas e é maior entre as mulheres. Também, o número de idosos que apresentam algum tipo de deficiência física ou mental é muito mais alto entre 
os institucionalizados do que nos demais idosos (CAMARANO, 2005).

Assim sendo, não se pode considerar este tipo de instituição como apenas de assistência social como vem sendo definida pelo Estado, através da Política Nacional do Idoso, que estabelece em seu artigo 4ํㅡㄹ parágrafo único: "É vedada a permanência de portadores de doenças que necessitem de assistência médica e de enfermagem permanente em instituições asilares de caráter social" (BRASIL, 1994).

As instituições de longa permanência para idoso, assim como os demais serviços de cuidados de longo prazo, prestam assistência não só social, mas também de saúde, sendo um serviço híbrido (KANE e KANE, 1987 e BORN e BOECHAT, 2002).

Vários estudos descrevem os motivos que levam à institucionalização do idoso, sendo estes: ausência de familiares ou familiares sem tempo para cuidar, incompatibilidade de gerações, situação socioeconômica precária, elevado grau de dependência para execução das atividades de vida diária, necessidade de reabilitação após período de internação hospitalar e opção pessoal (PAVARINI, 1996; BOECHAT, 1996; CHAIMOWICZ e GRECO, 1999, CALDAS, 2003).

BRITO e RAMOS (2002) pontuam que as instituições de longa permanência para idosos são uma opção de cuidados para pessoas mais frágeis, muito dependentes ou que, por razões médico-sociais, não podem ficar em suas residências. Complementam informando que, no geral:

(....) recebem pacientes incapacitados com diferentes enfermidades e aqueles que vivem sozinhos, cujos familiares não podem garantir os cuidados necessários no interior das famílias. 
Nos países desenvolvidos estima-se que cerca de $5 \%$ das pessoas maiores de 65 anos estão institucionalizadas, número este que aumenta entre os idosos mais velhos (p. 329).

Segundo MORAES (2002), a institucionalização no Brasil é conseqüência do acúmulo de sucessivas deficiências que ocorrem ao longo do ciclo vital de diversas pessoas, deficiências estas que se agravam com o passar do tempo. Além disso, conforme SALDANHA (2004), não se tem, em quantidade suficiente, outros equipamentos de prestação de serviços aos idosos em modalidades diversas como centro-dia, hospital-dia, centro de convivência, casa-lar e atendimento domiciliar.

Historicamente, como dito anteriormente, as instituições de longa permanência para idosos, chamadas de asilos, foram criadas para prestar atendimento assistencial de forma caritativa, isto é criada para os pobres (PAVARINI, 1996). Também, com o passar dos anos, foi socialmente incorporada à idéia de abandono e rejeição (NOVAES, 2005).

Contudo, nas últimas décadas, várias mudanças, mesmo que mínimas, ocorreram na forma de se administrar e rotular as instituições de longa permanência para idoso. BALTES et al. (1994) já diziam que as instituições para idosos podem se estruturar para promover um envelhecimento positivo, e não necessitam apresentar características de instituições totais.

BAHURY (1996) conclui, em seu estudo, que a instituição de longa permanência para idosos não deve ser entendida, tão somente, como uma instituição total. Ao contrário deste conceito, segundo a autora, estão os relatos de idosos que vislumbram, nestas instituições, um espaço para 
resgatar uma sociabilidade perdida, experimentando novas formas de interação; um espaço para desenvolver novas habilidades, através das atividades oferecidas e, conseqüentemente, propiciar novas formas de expressar o seu eu.

Compactuando com esta idéia, MARTINEZ (2003) afirma que idosos institucionalizados relatam a opção de residir em instituições de longa permanência como a possibilidade de resgatar uma vida social ativa, de convívio com um grupo de pessoas de mesma idade, além de evitar um conflito familiar de gerações e o sentimento de ser um estorvo para os filhos e familiares.

Independentemente do motivo que levou o idoso a ingressar em uma instituição de longa permanência, esta instituição deve-lhe assegurar condições dignas de vida e cidadania, respeitando sua autonomia (NOVAES, 2005).

Para tanto, é necessário qualificar a equipe que presta cuidado aos idosos institucionalizados. NOVAES (2005) relata que a falta de conhecimento específico para lidar com idosos poderá reforçar, ou até incluir, um comportamento dependente nos indivíduos cuidados.

Complementando esta afirmação, MARTINEZ (2003) considera que os indivíduos que prestam qualquer tipo de cuidado aos idosos institucionalizados, além das competências técnicas e científicas, devem ter habilidades humanas como dedicação, respeito e carinho, o que irá garantir eficácia e eficiência no cuidado prestado. 


\subsection{SAÚDE E CUIDADO À SAÚDE}

A compreensão do que seja saúde evoluiu nos últimos anos. Em meados do século passado, a Organização Mundial da Saúde (OMS) definiu saúde como o estado completo de bem - estar físico, mental e social e não apenas como a ausência de doença (ALMEIDA FILHO, 2000).

Este conceito recebeu críticas de vários autores. Todos apresentam o mesmo questionamento: como se chegar ao "completo" bem-estar, definido como perfeito estado de satisfação física, mental e social. Sabe-se que o perfeito é intangível, pois somos humanos e imperfeitos. Como seria possível garantir saúde à população mundial que atualmente sofre, de forma esmagadora, de doenças crônicas e como garantir bem-estar social em sociedades onde as desigualdades sociais são gritantes (SEGRE e FERRAZ, 1997; ALMEIDA FILHO, 2000 e ROSA et al., 2005).

SEGRE e FERRAZ (1997) sugerem uma definição para saúde como: "um estado de razoável harmonia entre o sujeito e a sua própria realidade" (p.539).

ROSA et al. (2005) sugerem: "é a habilidade que o indivíduo tem de superar incapacidades, utilizando o meio onde vive a seu favor, tendo a aptidão de responder satisfatoriamente a certas variações do mesmo" ( $p$. $579)$.

Em 1986, durante a Primeira Conferência Internacional sobre a Promoção de Saúde, em Ottawa, a definição de saúde foi pontuada como: 
La salud se percibe pues, no como el objetivo, sino como la fuente de riqueza de la vida cotidiana. Se trata por tanto de um concepto positivo que acentúa los recursos sociales y personales así como las aptitudes físicas. Por consiguinte, dado que el concepto de salud como bienestar transciende la Idea de formas de vida sanas, la promoción de la salud no concierne exclusivamente al sector sanitário (OMS, 1986, p.1).

Esta definição de saúde foi incorporada por diversos países, inclusive o Brasil, conforme se pode verificar na Constituição da República (BRASIL, 1988), em seu artigo 196, que diz: "A saúde é direito de todos e dever do Estado, garantido mediante políticas sociais e econômicas que visem à redução do risco de doença e de outros agravos e ao acesso universal igualitário às ações e serviços para sua promoção, proteção e recuperação".

Neste contexto, a saúde é conceituada não apenas como ausência de doença, mas também como expressão da forma como vivem os indivíduos.

Segundo DALLARI e FORTES (1997), o indivíduo deve ter a liberdade de escolher como quer viver, isto é, como será sua relação com o trabalho, com o meio ambiente, em que cidade quer viver e, quando necessitar, qual o tipo de tratamento e recursos médicos a que se submeterá.

Desta feita, o Estado procura garantir aos indivíduos o direito à cidadania, expresso claramente na "Carta dos direitos dos usuários de saúde" (MINISTÉRIO DA SAÚDE, 2006b), onde consta, em seu preâmbulo:

A carta que você tem nas mãos baseia-se em seis princípios básicos de cidadania. (...) Princípios desta carta: I - todo cidadão tem direito ao acesso ordenado e organizado aos sistemas de saúde; II - todo cidadão tem direito a tratamento adequado e efetivo para seu problema; III - todo cidadão tem direito ao atendimento humanizado, acolhedor e livre de qualquer discriminação; IV - todo cidadão tem direito a atendimento que respeite a sua pessoa, seus valores e seus direitos; V - todo cidadão também tem responsabilidades para que seu tratamento aconteça de forma adequada; e VI - todo cidadão tem direito ao comprometimento dos gestores de saúde para que os princípios 
anteriores sejam cumpridos.

Para que estes direitos sejam assegurados, a participação popular na gestão do sistema de saúde foi garantida, através da criação dos Conselhos de Saúde, sendo estes formados por representantes do governo, prestadores de serviços, profissionais de saúde e usuários. Tem caráter permanente e deliberativo, atuando na formulação de estratégias e no controle da execução da política de saúde, incluindo questões econômicas e financeiras (BRASIL, 1990).

DALLARI e FORTES (1997) concluem que apenas quando um Estado for desenvolvido econômico, social e culturalmente poderá oferecer saúde, de forma eqüitativa para todo o povo.

Tendo como base o conceito amplificado de saúde, o cuidado à saúde não pode mais ser definido como um conjunto de ações técnicas, embasadas cientificamente, direcionadas às pessoas com o intuito de curálas ou mantê-las sem doenças (AYRES, 2004; WALDOW, 2004; BRUM et al, 2005).

Segundo AYRES (2004) cuidado de saúde é "uma interação entre dois ou mais sujeitos visando o alívio de um sofrimento ou o alcance de um bem-estar, sempre mediada por saberes especificamente voltados para essa finalidade" (p. 74).

Neste sentido, o cuidado à saúde não se limita a um aspecto técnico, mas também em atitudes e sentimentos. As profissões procuram profissionalizar a capacidade humana de cuidar, utilizando, para isso, conhecimentos teórico-práticos necessários a cada uma (WALDOW, 2004). 
Segundo a Teoria da Diversidade e Universalidade do Cuidado, de Madeleine M. Leininger, o cuidado profissional é definido como "o fenômeno abstrato e concreto relacionado com a assistência, o apoio ou a capacitação de experiências ou de comportamentos para outros ou por outros com necessidades evidentes ou antecipadas para melhorar uma condição humana ou forma de vida" (GEORGE, 2000, p. 299).

Analisando-se os conceitos descritos sobre saúde e cuidados à saúde, encontra-se a Teoria das Necessidades Humanas Básicas de Wanda de Aguiar Horta que define saúde como sendo a manutenção do estado de equilíbrio dinâmico no tempo e espaço do ser humano. Os desequilíbrios provocam no indivíduo necessidades que se expressam por estados de tensão, que podem ser conscientes ou inconscientes, e que levam à busca da satisfação das necessidades afetadas, visando à manutenção do equilíbrio dinâmico no tempo e espaço. Quando as necessidades não são atendidas, ou atendidas de forma insatisfatória, geram desconforto que, se prolongado, causa doença. As necessidades são decorrentes dos desequilíbrios homeodinâmicos dos fenômenos vitais (HORTA, 1979).

Segundo HORTA (1979), o cuidado à saúde deve ocorrer quando o ser humano não contempla a satisfação de suas necessidades básicas. Ele deve ser assistido no atendimento destas necessidades com o intuito de torná-lo independente destas, quando possível, pelo ensino do autocuidado.

Quanto ao autocuidado, OREM (1991) conceitua-o como a prática de atividades que os indivíduos desenvolvem em benefício próprio, visando à manutenção da saúde, do bem estar e da vida. A capacidade de se 
autocuidar é afetada por fatores condicionantes básicos, como a idade e o sexo, por exemplo, além de exigir a preservação da capacidade funcional e cognitiva do indivíduo. Assim, a necessidade de auxílio profissional virá quando o indivíduo não for capaz de realizar, em benefício próprio, atividades para manter sua vida, sua saúde e seu bem-estar.

Desta forma, a falta de capacidade do indivíduo de realizar o autocuidado gera desequilíbrio dinâmico de fenômenos vitais, isto é, a não satisfação de suas necessidades humanas básicas, o que pode demandar uma assistência profissional qualificada para que este indivíduo recupere seu equilíbrio.

Segundo HORTA (1979), as necessidades humanas básicas são divididas em três categorias: as necessidades psicobiológicas, as necessidades psicossociais e as necessidades psicoespirituais. Estas necessidades são inter-relacionadas, isto é, em maior ou menor intensidade, todas elas sofrem alterações quando uma delas não está a contento, seja por falta ou excesso.

A seguir, descreve-se o conteúdo de cada uma das categorias de necessidades humanas básicas, segundo definições de HORTA (1979).

- Necessidades psicobiológicas - oxigenação, hidratação, nutrição, eliminação, sono e repouso, exercício e atividade física, sexualidade, abrigo, mecânica corporal, motilidade, cuidado corporal, integridade cutâneo-mucosa, integridade física, regulação (térmica, hormonal, neurológica, hidrossalina, eletrolítica, imunológica, crescimento celular, vascular), locomoção, percepção (olfativa, visual, auditiva, tátil, gustativa, dolorosa), ambiente e terapêutica.

- Necessidades psicossociais - segurança, amor, liberdade, comunicação, aprendizagem (educação à saúde), gregária, recreação, lazer, espaço, orientação no tempo e espaço, aceitação, auto-realização, auto-estima, participação, auto-imagem, atenção. 
- Necessidades psicoespirituais - religiosa ou teológica, ética ou de filosofia de vida (p. 40).

Mesmo sendo considerada por muitos autores como uma teoria incompleta, a Teoria das Necessidades Humanas Básicas de Wanda de Aguiar Horta proporciona uma visão de enfermagem e de cuidados de enfermagem que, unida, ou não, à Teoria do Autocuidado de Dorothea Orem, possibilita um referencial teórico capaz de fundamentar a prática de enfermagem. Um exemplo do afirmado acima é a utilização da teoria de Wanda de Aguiar Horta, desde a década de setenta, para fundamentar as ações de enfermagem desenvolvidas no Hospital de Clínicas de Porto Alegre (LONGARAY et al., 2008).

\subsection{CUIDADO À SAÚDE DO IDOSO}

Quando se fala em cuidado à saúde do idoso, um conceito muito importante a ser considerado é o de capacidade funcional. Segundo BALTES e SILVERBERG (1995), capacidade funcional é a capacidade individual para realizar as atividades de vida diária (AVD), isto é, as atividades cotidianas do dia-a-dia. Os autores informam que há diferentes graus de incapacidade funcional, dependendo de quantas e de quais atividades de vida diária estão sendo analisadas.

PAVARINI e NERI (2000), Caldas (2003) e DUARTE e LEBRÃO (2006) relacionam as atividades de vida diária em três grupos: atividades 
básicas de vida diária - tarefas próprias do auto cuidado, como se alimentar, por exemplo; atividades instrumentais da vida diária - necessária para uma vida independente na comunidade; e atividades avançadas de vida diária atos complexos, automotivacionais, como o trabalho, por exemplo.

Semelhante ao descrito pelas autoras é encontrado no conteúdo da Política Nacional de Saúde da Pessoa Idosa, publicada em 2006, aprovada pela Portaria MS no 2.528 , que classifica o idoso em três categorias distintas, de acordo com sua capacidade funcional: idoso independente, idoso com potencial para desenvolver fragilidade, idoso frágil ou em situação de fragilidade (MINISTÉRIO DA SAÚDE, 2006a). A seguir, descreve-se cada categoria conforme determinação da portaria acima citada.

A primeira categoria, de idoso independente, engloba os idosos que são capazes de realizar, sem dificuldades, todas as atividades básicas de vida diária (AVD), sendo estas: tomar banho, vestir-se, usar o banheiro transferir-se da cama para cadeira, ser continente e alimentar-se com a própria mão (MINISTÉRIO DA SAÚDE, 2006a).

É considerado idoso com potencial para desenvolver fragilidade aquele que apresentar alguma dificuldade em realizar atividades instrumentais de vida diária (AIVD) - preparar refeições, controlar a própria medicação, fazer compras, controlar o próprio dinheiro, usar o telefone, fazer pequenas tarefas e reparos domésticos, e sair de casa sozinho utilizando uma condução coletiva (MINISTÉRIO DA SAÚDE, 2006a).

Idoso frágil ou em situação de fragilidade é aquele que se encontra acamado, com doenças sabidamente causadoras de incapacidade funcional 
(acidente vascular encefálico, síndromes demenciais e outras doenças neurodegenerativas, etilismo, neoplasia terminal, amputações de membros), que esteve hospitalizado recentemente por qualquer razão, que se encontra com pelo menos uma incapacidade funcional básica, que viva situação de violência doméstica ou aquele com mais de 75 anos. É importante considerar que a condição do idoso residente em uma instituição de longa permanência já o classifica como idoso fragilizado (MINISTÉRIO DA SAÚDE, 2006a).

Cabe colocar que, o conceito de fragilidade expresso acima é o adotado pelo Ministério da Saúde para definir uma política pública de atenção à pessoa idosa. De acordo com TEIXEIRA (2008), fragilidade é um conceito que engloba fatores multidimensionais (fatores biológicos, psicológicos e sociais no curso da vida), ultrapassando o domínio físico, não devendo ser confundida com vulnerabilidade ou o próprio conceito de envelhecimento.

As pessoas que despendem cuidados a idosos devem se valer, além de todos os conceitos que foram expostos anteriormente, de informações transmitidas pelos próprios idosos através de sua história de vida. Segundo PAPALÉO NETTO e PONTE (1997), o cuidar da saúde se baseia, entre outras coisas, na preservação da dignidade do ser humano enquanto ser biológico e biográfico.

O idoso, por ter vivido décadas, é um ser "muito mais" biográfico que biológico (o que influencia diretamente a forma como deve ser cuidado), o que o torna cada vez mais único e diferenciado, mesmo que algumas de 
suas necessidade sejam idênticas as de outros idosos (BERGER e MAILLOUX-POIRIER, 1995).

PASCHOAL (2006) compactua com tal afirmação quando diz que em nenhum outro grupo etário existem tantas diferenças individuais. Segundo o autor, estas diferenças estão presentes em todos os tipos de características: física, mental, psicológica, socioeconômica e de saúde, levando à necessidade de um alto grau de individualização de julgamentos sobre qualidade de vida e necessidade de cuidados.

Portanto, a saúde da pessoa idosa não pode ser reduzida a aspectos físicos, mas, sim, entendida como uma expressão do seu modo de vida, isto é, suas condições materiais devem ser analisadas sob a luz de suas experiências de vida (MORAES, 2002).

Desta forma, o cuidado ao idoso deve ser fundamentado, entre outros princípios, mas, prioritariamente, em promover e proteger a saúde, prevenir complicações do estado patológico, prevenir a desinserção social e a deterioração da personalidade, facilitar a manutenção da identidade e da autonomia, reduzir a inatividade intelectual, física e social, auxiliar a manutenção e o desenvolvimento de novas capacidades, permitir a manutenção do poder de decisão sobre si próprio, na medida do possível e propiciar meios que facilitem o engajamento social (BERGER e MAILLOUXPOIRIER, 1995).

Estes princípios norteadores devem ser seguidos pela família cuidadora ou pelos profissionais que atendem o idoso. Segundo PAVARINI (1996), em instituições de longa permanência para idosos, o papel da 
enfermagem é crucial, pois a assistência aos idosos é, majoritariamente, realizada por esta equipe.

Assim, os cuidados à saúde desenvolvidos pela equipe de enfermagem, segundo a mesma autora, parecem ser responsáveis, diretamente, pela qualidade de vida dos idosos institucionalizados.

Portanto, neste estudo, considerou-se como cuidados à saúde, todas as atividades desenvolvidas aos idosos pela equipe de enfermagem, de forma intencional (consciente), planejada (organizada) e científica (conjunto de conhecimentos obtidos através de experiências comprovadas e aprovadas pela comunidade de enfermagem), tendo por objetivos a satisfação das suas necessidades humanas básicas e a promoção do autocuidado. Estas atividades podem ser de fazer o que o idoso não pode fazer por si mesmo, auxiliá-lo quando parcialmente incapacitado ou orientálo e supervisioná-lo quando apto a realizá-las. 


\section{OBJETIVO}

- Conhecer o significado atribuído pela equipe de auxiliares de enfermagem de uma instituição de longa permanência filantrópica do município de São Paulo ao termo "cuidados à saúde" e sua relação com as atividades por eles desenvolvidas. 


\section{MÉTODOS}

\subsection{TIPO DE ESTUDO}

No sentido de se atingir os objetivos propostos, optou-se pela realização de um estudo quanti-qualitativo através de pesquisa exploratória, não probabilística, por conveniência do pesquisador.

A pesquisa qualitativa trabalha com valores, hábitos, crenças, atitudes, representações e opiniões. É adequada quando necessitamos aprofundar o conhecimento sobre processos específicos de determinados grupos, possíveis de serem abarcados intensamente, não sendo reduzidos à operacionalização de variáveis (MINAYO e SANCHES, 1993).

MARTINELI (1994) ressalta que nas pesquisas qualitativas “(...) ao invés de trabalharmos com grandes temas, com grandes cronologias, o fazemos de forma mais localizada. Trabalhamos com os fatos de forma a poder aprofundar tanto quanto possível a análise (...) priorizamos (...) os fatos que são mais próximos do sujeito e que repercutem diretamente na sua vida" (p. 13).

Para tanto, consideramos que a realização de grupos focais é a técnica mais indicada, para a coleta de dados. Segundo IERVOLINO e PELICIONI (2001), a técnica de grupos focais possibilita, além de uma interação entre os participantes e o pesquisador, uma coleta de dados 
objetiva, com discussões focadas em tópicos específicos.

Como técnica, é uma entrevista em grupo que possibilita a interação entre seus componentes e propicia o desvelar de percepções e dados que, em entrevistas individuais ou questionários, talvez não fossem acessíveis (NOGUEIRA-MARTINS e BÓGUS, 2004).

Esta técnica tem por finalidade gerar uma gama de respostas e formular hipóteses, e não firmar, necessariamente, um discurso conclusivo sobre as questões pesquisadas (ASCHIDAMINI e SAUPE, 2004).

\subsubsection{Estudo Preliminar}

Foi realizado um teste piloto, antes da realização da coleta de dados, em uma instituição de longa permanência para idosos localizada em um município da Grande São Paulo, para verificar se o guia de temas estava adequado aos objetivos da pesquisa, isto é, se as questões norteadoras proporcionariam discussões cujos conteúdos versassem sobre o tema da pesquisa. O grupo foi composto por oito (8) auxiliares de enfermagem e as questões propostas se mostraram adequadas para a obtenção das falas dos sujeitos. 


\subsection{CAMPO E POPULAÇÃO}

O estudo foi desenvolvido em uma instituição filantrópica de longa permanência para idosos, situada na região Sul no município de São Paulo.

Foi escolhida uma instituição filantrópica, especificamente, pois através das discussões no Fórum de Instituições de Longa Permanência para Idosos, formado majoritariamente, por instituições filantrópicas, a preocupação com a busca da qualidade do cuidado prestado no sentido de melhorar o atendimento e a qualidade de vida dos idosos residentes é uma constante, apesar das dificuldades financeiras por elas enfrentadas.

A instituição em que estes profissionais trabalham foi identificada em listagem de instituições de longa permanência para idoso localizadas no município de São Paulo, obtida através do Conselho Regional de Enfermagem de São Paulo, datada de 6 de junho de 2006. A listagem conta com um total de duzentos e doze (212) instituições, sendo cento e noventa e três (193) privadas e dezenove (19) filantrópicas. Das dezenove filantrópicas, apenas um, tem o profissional enfermeiro, certificado como responsável técnico de enfermagem, no seu quadro de pessoal, definindo assim, a opção por esta insituição.

Acredita-se que 0 adequado desenvolvimento das atividades de enfermagem desenvolvidas a idosos institucionalizados é facilitada com a presença do enfermeiro na equipe. Este profissional, além dos aspectos de cunho legal, através de seu desempenho no processo de cuidar, influencia e 
direciona as atividades desenvolvidas pelos outros profissionais de sua equipe.

Trata-se de uma instituição totalmente gratuita, filantrópica, sobrevivendo apenas de doações financeiras de pessoas físicas e jurídicas, sem nenhum auxílio governamental. Os residentes que recebem aposentadoria ou o Benefício de Prestação Continuada contribuem com 70\% desta; alguns, como forma de doação, oferecem à instituição o restante.

A insituição conta com diversos voluntários para o desenvolvimento de atividades administrativas, de lazer e entretenimento e atualmente é campo para realização de vários estudos científicos em diferentes áreas da saúde.

Não são aceitos, para a admissão na instituição, idosos dependentes ou semi-depententes, apenas aqueles considerados independentes, isto é, que desenvolvem sozinhos todas as atividades de vida diária. Porém, se esta condição for alterada para qualquer das duas outras anteriormente citadas, o idoso tem garantia de que não será desvinculado da residência, a menos que sua condição exija cuidados técnicos intensivos.

Além disso, os idosos devem comprovar a precariedade de recursos materiais, incluindo o auxílio familiar, que impossibilite a manutenção de sua sobrevivência de forma autônoma.

A instituição foi fundada no ano de 1950 com o intuito de abrigar idosos sem recursos, que viviam em estado de abandono. A instituição abriga, atualmente, oitenta e dois residentes (82), sendo trinta e três (33) homens e quarenta e nove (49) mulheres. 
Segundo informações da enfermeira responsável pela equipe de enfermagem da instituição, estes idosos estão divididos, segundo sua dependência para realização de atividades de vida diária, em: cinqüenta e dois (52) independentes, sete (7) semi-dependente (necessitam de auxílio para se alimentar, se locomover e se higienizar) e vinte e três (23) dependentes para todas as atividades.

A instituição se localiza em uma ampla área verde, dividida em oito (8) pavilhões que acomodam, em média, dezoito (18) leitos. Tem, ainda, dois (2) refeitórios, uma (1) cozinha industrial, um (1) consultório odontológico, um (1) consultório de enfermagem, dois (2) consultórios médicos, uma (1) sala de fisioterapia e terapias complementares, além de áreas ocupacionais para desenvolvimento de oficinas de trabalhos manuais e de integração social.

A equipe multiprofissional de saúde que compõe a instituição é formada por: uma (1) enfermeira, dezoito (18) auxiliares de enfermagem, uma (1) cuidadora, uma (1) assistente social, uma (1) nutricionista, quatro (4) médicos, sendo dois (2) geriatras e dois (2) especializandos. Além destes, recebem estagiários dos cursos de graduação em enfermagem, fisioterapia, psicologia e fonoaudiologia.

A população deste estudo foi composta pelos auxiliares de enfermagem que formam a equipe de enfermagem da referida instituição.

Foram excluídas da amostra, por serem as únicas em suas categorias profissionais, a cuidadora de idosos, e a enfermeira responsável pela equipe de enfermagem. Esta última, além de ser a única profissional de nível superior que compõe a equipe, também é responsável tecnicamente pelas 
atividades desenvolvidas pelos demais participantes da pesquisa. Desta forma, buscou-se homogeneizar os grupos, não em relação às percepções, mas com vistas em proporcionar conforto e liberdade para participação nas discussões, atitude esta recomendada por IERVOLINO e PELICIONI (2001). Adotou-se, como critério de inclusão, ter mais de um ano de vínculo com a instituição, pois, acredita-se que, dessa forma, os sujeitos da pesquisa teriam facilidade em fornecer as informações solicitadas já que conheciam as rotinas do trabalho e a instituição há certo tempo, além de suas obrigações para com ela.

Segundo o Departamento de Pessoal da instituição, todos os dezoito (18) auxiliares de enfermagem que compunham a equipe trabalhavam na mesma há mais de um ano. Do total, cinco (5) não participaram da pesquisa porque não estavam disponíveis no momento da coleta de dados: um (1) profissional encontrava-se doente, um (1) em gozo de férias, uma (1) profissional em licença maternidade e dois (2) profissionais encontravam-se acompanhando residentes em atividades externas. Considerando a impossibilidade de agendamento de novo grupo focal, por parte da ILPI para a inclusão desses profissionais, participaram deste estudo, treze auxiliares de enfermagem que desenvolvem atividades de cuidados à saúde aos idosos institucionalizados, contratados há mais de um ano.

Os grupos focais foram realizados na instituição, em data e horário convenientes para o serviço. 


\subsection{COLETA DE DADOS}

Os dados foram coletados por meio de uma entrevista com a enfermeira que é a responsável técnica pela equipe de enfermagem e pelo desenvolvimento de grupos focais.

De acordo com entrevista realizada previamente com a enfermeira responsável pela equipe de enfermagem da instituição foram organizados dois grupos, um para cada plantão (dias pares e ímpares), para garantir que todos os profissionais de enfermagem que desejassem participar da pesquisa, poderiam fazê-lo, já que a adesão dos mesmos à pesquisa deveria ser voluntária.

As datas da realização dos grupos foram agendadas em dias consecutivos, durante a primeira semana de março de dois mil e oito, na própria instituição, pois, segundo a enfermeira responsável, haveria uma reunião técnica para atualização dos profissionais de sua equipe, sendo possível disponibilizar certo tempo para realização da pesquisa.

As sessões tiveram a duração de uma hora e quinze minutos e uma hora, respectivamente, para que os participantes não se sentissem desconfortáveis, o que poderia interferir nas discussões e, conseqüentemente, prejudicar os resultados (DALL'AGNOL e TRENCH, 1999 e IERVOLINO e PELICIONI, 2001), além de não afetar o andamento das atividades desenvolvidas na instituição.

Segundo ASCHIDAMINI e SAUPE (2004), o número de sessões varia 
de acordo com o interesse da pesquisa e sua complexidade, podendo ser alterado após coleta de dados.

Cada grupo, a priori, seria composto por dez (10) e nove (9) profissionais de enfermagem, respectivamente, porém, o primeiro grupo foi formado por sete (7) e o segundo grupo foi formado por seis (6) integrantes. Conforme relatado anteriormente, cinco (5) auxiliares de enfermagem não estavam disponíveis, por diferentes razões, para participar da coleta de dados.

Apesar de vários autores indicarem como ideal a variação entre oito e dez participantes (DALL'AGNOL e TRENCH, 1999; IERVOLINO e PELICIONI, 2001 e MEIER e KUDLOWIEZ, 2003), esta definição de número de participantes deu-se pelo número de auxiliares de enfermagem que trabalham na instituição, dispostos e disponíveis a participaram da pesquisa. DALL'AGNOL e TRENCH (1999) informam que quando a pesquisa pretende maximizar a expressão de cada participante, um grupo pequeno é melhor.

$\mathrm{Na}$ tentativa de se evitar vieses e ser coerente, os dados foram coletados por duas outras enfermeiras (uma moderadora e uma observadora), neste estudo, denominadas "auxiliares de pesquisa", dado que a pesquisadora é fiscal do Conselho Regional de Enfermagem de São Paulo que havia realizado fiscalização do exercício profissional dos trabalhadores de enfermagem na instituição anteriormente, o que poderia prejudicar a obtenção das informações.

A coerência minimiza tanto tendencionismos (LOBIONDO-WOOD e HABER, 2001) quanto à ansiedade dos sujeitos quando mais de uma 
pessoa coleta os dados (WEINERT e BURMAN, 1996).

As auxiliares de pesquisa são enfermeiras com experiência profissional de mais de dez anos de formação e já tinam experiência na técnica de grupos focais e, concordando com COLLINS et al. (1988), que afirmam que o pesquisador deve treinar e supervisionar os auxiliares na coleta de dados, realizou-se uma reunião prévia, em que as mesmas foram orientadas sobre os objetivos e a metodologia a ser utilizada na pesquisa. Após a realização de cada grupo, a pesquisadora realizou reuniões com as auxiliares de pesquisa para a obtenção do material coletado (gravações e relatório da observadora) e levantamento de suas percepções.

Foi realizada uma entrevista com a enfermeira para obtenção de informações sobre a organização administrativa do serviço de enfermagem na instituição e sobre os documentos norteadores das atividades desta equipe.

Como instrumento de coleta de dados para o grupo focal foi construído um guia de temas para nortear as discussões, composto por três perguntas: 1 - Quais as atividades que você desenvolve nesta instituição? 2 - Para você, o que são cuidados à saúde? 3 - Dentre as atividades que você desenvolve na instituição, quais você classifica como cuidados à saúde?

Para obtenção de dados sobre aspectos sociais, profissionais e ocupacionais, foi solicitado a cada sujeito da pesquisa, o preenchimento de um questionário (anexo 1) com questões relacionadas à caracterização social do grupo, formação profissional e história ocupacional. 
As sessões foram gravadas em aparelho $\mathrm{mp} 3$, transferidas para $\mathrm{CD}$ e transcritas na íntegra. A transcrição e análise dos dados foram realizadas pela própria pesquisadora, ficando apenas a coleta de dados, isto é, a realização dos grupos focais, a cargo das auxiliares de pesquisa.

A transcrição dos depoimentos da forma oral para a escrita foi criteriosa e despendeu cerca de 30 horas, em média, para a sua realização.

\section{4 - REFERENCIAL METODOLÓGICO}

Após a transcrição, procedeu-se a análise dos dados, segundo o método de Análise de Conteúdo, proposto por BARDIN (1977).

A definição de análise de conteúdo, segundo BARDIN (1977), é:"um conjunto de técnicas de análise de comunicação visando obter, por procedimentos sistemáticos e objetivos de descrição dos conteúdos das mensagens, indicadores que permitam a inferência de conhecimentos relativos às condições de produção/reprodução destas mensagens" (p. 42).

Assim sendo, a análise de conteúdo busca conhecer o que está por trás do que foi dito; busca articular o conteúdo dos textos analisados com os fatos que determinaram o discurso, através da dedução lógica (BARDIN, 1977).

A sistematização de análise dos dados, segundo BARDIN (1977) obedece a três etapas: a pré-análise (o material das entrevistas deverá ser 
submetido à leitura fluente, buscando-se o sentido universal dos discursos), a descrição analítica (com a análise profunda dos discursos, busca-se identificá-los e agrupá-los, tomando como base as hipóteses e o referencial teórico. Esta classificação genérica, tendo como base um grupo de elementos convergentes, denomina-se categorização), e a interpretação referencial (neste momento se estabelecerá relação entre o objeto da análise e seu conteúdo mais amplo, podendo levar a ponderações que façam emergir novos padrões nas estruturas e relações estudadas).

Desta forma, depois de repetidas e exaustivas leituras do material transcrito, os dados foram divididos, de acordo com os temas surgidos, em dois grupos: definição de cuidados à saúde e cuidados à saúde desenvolvidos por auxiliares de enfermagem. Cada grupo teve seus temas reorganizados, isto é, foram configuradas categorias resultantes da classificação de conceitos semelhantes obtidos através dos discursos dos sujeitos.

$\mathrm{Na}$ etapa de categorização, foi utilizada, como referencial teórico, a Teoria das Necessidades Humanas Básicas de Wanda de Aguiar Horta.

\section{5 - ASPECTOS ÉTICOS DA PESQUISA}

Os sujeitos da pesquisa, bem como o responsável técnico da instituição, foram esclarecidos sobre os objetivos e a metodologia de coleta 
de dados, conforme preconiza a Resolução 196/96 do Conselho Nacional de Saúde (CNS, 1996), visando, desta forma, obter consentimentos livres e esclarecidos dos sujeitos e autorização institucional para realização do estudo.

Para tanto, anteriormente ao agendamento das entrevistas, foram entregues à Instituição o Termo de Compromisso da Pesquisadora (anexo 2) e obtido o Termo de Concordância da Instituição (anexo 3).

Antes de cada entrevista, foi apresentado a cada sujeito, o Termo de Consentimento Livre e Esclarecido (anexo 4) que, após ter sido apresentado e compreendido foi assinado pelos mesmos.

Pode-se assegurar que não haveria riscos para a instituição ou para os sujeitos, e foi garantido o anonimato de ambos.

O projeto da pesquisa foi encaminhado ao Comitê de Ética e Pesquisa da Faculdade de Saúde Pública da Universidade de São Paulo COEP, que analisou e aprovou a mesma, conforme Ofício COEP/03/08, Protocolo 1704, de 16 de janeiro de 2008 (anexo 5). 


\section{RESULTADOS E DISCUSSÃO}

Considerando que este estudo foi realizado em uma única instituição de longa permanência e com uma população em número reduzido, os resultados descritos a seguir apresentam certas limitações, impedindo generalizações.

A instituição estudada apresenta dezenove (19) profissionais ligados às atividades de enfermagem em seu quadro de funcionários. Destes, uma (1) é enfermeira e dezoito (18) são auxiliares de enfermagem. Segundo informações da enfermeira, ela desenvolve funções gerenciais da unidade de saúde existente na instituição, cabendo-lhe, principalmente, a coordenação, supervisão e orientação das atividades desenvolvidas pelos auxiliares de enfermagem e cuidador de idosos.

Não é rotina, o desenvolvimento de cuidados diretos aos idosos pela enfermeira, devido a grande demanda de tempo que outras atribuições assumidas pela mesma, anteriormente citadas, demandam. Aos auxiliares de enfermagem cabe a execução das atividades de enfermagem prescritas em prontuário pela enfermeira, isto é, a realização direta de cuidados de enfermagem.

BUJDOSO et. al. (2007) informam que a hierarquização do trabalho manual sobre o intelectual transforma os profissionais de nível universitário em uma elite privilegiada, com a detenção não apenas de saberes, mas também de salários maiores. 
Em estudo realizado sobre o processo de trabalho dos enfermeiros e auxiliares de enfermagem em um hospital escola, PEDUZZI e ANSELMI (2002) concluem que há uma nítida divisão entre concepção e execução do cuidado de enfermagem, onde os auxiliares de enfermagem não se apropriam dos saberes da profissão, cabendo-lhes, prioritariamente, a execução, isto é, o desenvolvimento de cuidados cotidianos, enquanto os enfermeiros se incumbem de tarefas de gerenciamento, seja dos cuidados ou da unidade.

Além disso, a Lei do Exercício Profissional da Enfermagem ㄲo 7.498 do ano de 1986, que estratifica as atribuições profissionais entre enfermeiros, técnicos de enfermagem e auxiliares de enfermagem, diz que estes dois últimos só podem desenvolver atividades profissionais sob supervisão do primeiro, e descreve que cabe aos auxiliares de enfermagem a realização de atividades básicas de enfermagem, como os cuidados de higiene e conforto (BRASIL, 1986).

Esta legislação reafirma a divisão social existente na categorização da profissão dos trabalhadores da enfermagem. BUJDOSO e colaboradores afirmam que "... a enfermagem contribui para a parte mais manual, que por sua vez foi redividida cabendo ao enfermeiro 'mais qualificado' o trabalho mais intelectual e aos auxiliares - "menos qualificados" - a parcela mais manual do trabalho" (2007: 1364).

Verificou-se, através de informação dada pela enfermeira responsável pela equipe de enfermagem, que a instituição não possui a descrição formal ou manual das atribuições de cada membro da equipe de enfermagem, 
sendo que o documento existente encontra-se desatualizado e em desuso. Hierarquicamente, a equipe de enfermagem está subordinada, através da enfermeira responsável, à diretoria da instituição.

Foram sujeitos desta pesquisa treze (13) auxiliares de enfermagem, que desenvolvem suas atividades em jornadas e turnos distintos, sendo eles de seis (6) horas diurnas e de doze (12) horas noturnas. Os profissionais desenvolvem suas atividades em horários fixos, existindo os folguistas que realizam a cobertura de folgas, férias e licenças dos profissionais fixos.

Os auxiliares de enfermagem são distribuídos entre os oito (8) pavilhões que compõem a instituição. Segundo informações da enfermeira responsável pela equipe, os idosos são alocados nestes pavilhões segundo seu grau de dependência e os auxiliares de enfermagem seguem uma escala de serviço que promove o rodízio entre os pavilhões.

Para melhor compreensão dos resultados obtidos, os mesmos serão descritos em duas partes, sendo a primeira destinada a caracterizar a equipe de enfermagem que atua na instituição de longa permanência para idosos segundo idade, sexo, tempo de formação profissional, tempo de atuação na instituição e período de trabalho, sendo analisados quantitativamente.

A segunda parte discorrerá sobre as representações do conceito de cuidados à saúde, e atividades relacionadas a este conceito desenvolvidas e expressas pelos profissionais de enfermagem. 


\subsection{CARACTERIZAÇÃO DA EQUIPE DE ENFERMAGEM}

Como se pode verificar no Quadro 1, dos treze (13) auxiliares de enfermagem entrevistados, a maioria tem mais que 40 anos de idade (7) e, a exemplo de estudo realizado em cinco instituições de longa permanência para idosos por REIS e CEOLIM (2007) que verificaram, entre 50 trabalhadores que prestavam cuidados diretos aos idosos, $94 \%$ eram do sexo feminino, eram mulheres onze (11) dos sujeitos de pesquisa.

Quadro 1 - Caracterização dos auxiliares de enfermagem, que trabalham em uma instituição de longa permanência para idosos (ILPI), segundo idade, sexo, tempo de formação profissional, tempo de atuação na instituição, período de trabalho, demais vínculos profissionais e experiência profissional anterior, São Paulo, março de 2008.

\begin{tabular}{|c|c|c|c|c|c|c|c|}
\hline $\begin{array}{l}\text { Auxiliares de } \\
\text { Enfermagem }\end{array}$ & $\begin{array}{l}\text { ldade } \\
\text { (anos) }\end{array}$ & Sexo & $\begin{array}{c}\text { Tempo de } \\
\text { formação (anos) }\end{array}$ & $\begin{array}{c}\text { Tempo de } \\
\text { atuação na ILPI }\end{array}$ & $\begin{array}{c}\text { Período de } \\
\text { trabalho }\end{array}$ & $\begin{array}{l}\text { Demais } \\
\text { vínculos }\end{array}$ & $\begin{array}{c}\text { Experiências } \\
\text { anteriores }\end{array}$ \\
\hline $\mathrm{AE} 1$ & 34 & $\mathrm{~F}$ & 3 & 2 anos 8 meses & manhã & não & nenhuma \\
\hline $\mathrm{AE} 2$ & 40 & $\mathrm{~F}$ & 4 & 1 ano 6 meses & folguista & não & nenhuma \\
\hline$A E 3$ & 30 & M & 7 & 3 anos & manhã & não & $\begin{array}{c}\text { atendimento } \\
\text { domiciliar }\end{array}$ \\
\hline $\mathrm{AE} 4$ & 55 & $\mathrm{~F}$ & 10 & 8 anos 3 meses & noite & não & creche \\
\hline $\mathrm{AE} 5$ & 31 & $\bar{M}$ & 2 & 1 ano 3 meses & folguista & não & nenhuma \\
\hline $\mathrm{AE} 6$ & 28 & $\mathrm{~F}$ & 5 & 2 anos & folguista & não & nenhuma \\
\hline $\mathrm{AE} 7$ & 42 & $\mathrm{~F}$ & 6 & 13 anos & manhã & não & nenhuma \\
\hline $\mathrm{AE} 8$ & 38 & $\mathrm{~F}$ & 5 & 2 anos & tarde & não & nenhuma \\
\hline $\mathrm{AE} 9$ & 38 & $\mathrm{~F}$ & 7 & 3 anos & tarde & não & nenhuma \\
\hline AE 10 & 49 & $\mathrm{~F}$ & 9 & 6 anos & manhã & não & nenhuma \\
\hline $\mathrm{AE} 11$ & 48 & $\mathrm{~F}$ & 10 & 6 anos & manhã & não & nenhuma \\
\hline AE 12 & 49 & $\mathrm{~F}$ & 5 & 3 anos & noite & $\begin{array}{c}\text { atendimento } \\
\text { domiciliar }\end{array}$ & outra ILPI \\
\hline$A E 13$ & 42 & $\mathrm{~F}$ & 5 & 2 anos 9 meses & noite & $\begin{array}{l}\text { atendimento } \\
\text { domiciliar }\end{array}$ & $\begin{array}{c}\text { atendimento } \\
\text { domiciliar }\end{array}$ \\
\hline
\end{tabular}

Em todas as sociedades, e ao longo da história da humanidade, o cuidado aos enfermos, as ações de auxílio aos velhos e os cuidados para o 
desenvolvimento e o crescimento das crianças é creditado às mulheres, bem como a manutenção de condições para o homem exercer suas atividades no trabalho (MELO, 1986; MANFFIOLETTI, et al 2006).

Corroborando com a afirmação acima, segundo estudo realizado pela enfermeira francesa Françoise Colliére, citada por OGUISSO (2007a), durante milhares de anos os cuidados não se vincularam a um ofício ou profissão, pois eram realizados por qualquer pessoa que desejasse auxiliar qualquer outra a garantir o necessário para continuar a viver.

Com o passar do tempo, estas atribuições foram divididas entre homens e mulheres, sempre visando garantir a existência e a sobrevivência. Inicialmente, às mulheres cabia cuidar dos filhos, dos feridos, dos idosos e da casa; aos homens prover o alimento através da caça, pesca ou colheita de frutos. Desta forma, surge a divisão sexuada do trabalho que, de acordo com as épocas e culturas, determinaram o lugar do homem e da mulher na vida econômica e social (OGUISSO, 2007a).

Assim, quando se fala sobre a enfermagem, entende-se porque ela é uma profissão predominantemente feminina, pois é a detentora da responsabilidade de cuidar dos clientes. Salientando as afirmações acima, cabe transcrever parte do texto publicado no jornal "Times" da Inglaterra, no ano de 1854, sobre a Guerra da Criméia (COELHO e col., 1997):

(...) Ó Inglaterra, não há, entre suas filhas, ninguém que queira cuidar dos soldados e ajudá-los no sofrimentos? A França enviou suas irmãs de caridade, que já estão ao lado dos feridos e dos agonizantes, dando-lhes o que só as mãos de uma mãe podem dar consolo, conforto e alívio. Temos de cair tão baixo dos franceses, em dedicação e amor? (pg. 4-5)

Dentre os treze (13) auxiliares de enfermagem entrevistados, sete (7) 
têm de um a cinco anos de formação, enquanto seis (6) profissionais têm entre seis e dez anos

Dentre os profissionais com menor tempo de formação, apenas dois (2) já trabalharam anteriormente em outra instituição de saúde (um em instituição de longa permanência para idosos e o outro um em atendimento domiciliar).

Dos treze (13) entrevistados, apenas dois (2) mantêm outro vínculo empregatício, sendo que ambos são formados há cincos anos e este outro vínculo se caracteriza por emprego em empresa de atendimento domiciliar.

De acordo com o tempo de atuação na instituição, verificou-se que nove (9) auxiliares de enfermagem trabalham na instituição entre um e três anos. Dois (2) exercem suas atividades na instituição há seis anos, e dois (2) há mais de oito anos.

A maioria dos auxiliares de enfermagem apresenta tempo de formação e tempo de atuação na instituição que varia entre um e cinco anos, e um e três anos, respectivamente.

O grande número de profissionais trabalhando a menos de três (3) anos na instituição corrobora a informação obtida através de conversa informal com os participantes do Fórum de Instituições de Longa Permanência para Idosos, de que há uma grande rotatividade de pessoal que compõe as equipes de enfermagem das instituições filantrópicas. 0 mesmo foi observado pela pesquisadora através das visitas fiscalizatórias realizadas pelo COREN-SP.

Segundo os participantes do referido Fórum, os profissionais de 
enfermagem de nível médio iniciam sua carreira profissional nessas instituições, desenvolvem habilidades e ganham tempo de experiência, requisitos quase sempre indispensáveis para a disputa de vaga de trabalho com melhor remuneração salarial, geralmente em instituições hospitalares.

REIS e CEOLIM (2007) identificaram, através de pesquisa com funcionários de cinco instituições totais que atendem idosos e que prestam cuidados diretos a estes, que o motivo maior pelo qual trabalham na assistência ao idoso é o desemprego.

Assim, levando-se em consideração o tempo de formação e o tempo de atuação na instituição e a informação de que apenas quatro (4) profissionais já tiveram ou têm experiências profissionais na área de enfermagem em outros serviços, observou-se que a maioria dos profissionais iniciou, e permanece desenvolvendo, suas atividades profissionais nesta instituição.

Ao relacionar-se os dados da idade com o tempo de formação e tempo de atuação na insituição, verifica-se que apenas três (3) auxiliares de enfermagem se formaram antes dos trinta anos de idade e que aqueles com idade maior, isto é, entre os quarenta e um (41) e cinqüenta e cinco (55) anos, são os que têm maior tempo de formação profissional e atuam há mais tempo na casa.

A maioria dos auxiliares de enfermagem trabalha no período da manhã: cinco (5) profissionais, seguidos por três (3) profissionais que trabalham no período da noite e três (3) na substituição, isto é, como folguistas, substituindo os outros profissionais que estão em seu dia de 
folga, não tendo horário definido. Apenas dois (2) trabalham no período da tarde.

Segundo relato da enfermeira, sobre as atividades desenvolvidas pela equipe de enfermagem junto aos clientes submetidos aos seus cuidados, cabe aos profissionais de enfermagem escalados no período da manhã, verificar os sinais vitais, realizar ou auxiliar nos banhos, fazer a arrumação dos leitos, realizar curativos, administrar a medicação prevista para este período e administrar ou auxiliar na alimentação de duas refeições - café da manhã e almoço.

PAVARINI (1996), em estudo realizado sobre a promoção ou manutenção da independência ou dependência a idosos institucionalizados em uma instituição de longa permanência do município de São Carlos, detectou que a maioria das atividades desenvolvidas pelos funcionários estava concentrada no período da manhã, entre as sete e doze horas. Segundo a autora, estas atividades eram: corte de unhas, café da manhã, banho, medicação e almoço, sendo as quatro últimas consideradas como atividades de rotina diária.

Observou-se neste estudo que à semelhança de outras instituições, apesar de serem intituladas como residências, as instituições de longa permanência para idosos se estruturam, organizacionalmente, de forma semelhante aos hospitais, onde as atividades são desenvolvidas seguindo calendário e horários pré-determinados. Segundo GOFFMAN (2005), neste tipo de instituição, todas as atividades são previamente esquematizadas, através de uma seqüência rígida de eventos que espelham um sistema 
formal de regras explícitas, direcionadas aos objetivos da instituição, possibilitando um controle maior sobre os indivíduos e facilitando a execução de atividades de cuidados aos residentes.

\subsection{REPRESENTAÇÕES SOBRE SAÚDE E CUIDADOS À SAÚDE EXPRESSAS PELOS PROFISSIONAIS DE ENFERMAGEM}

Através da leitura do material obtido nos grupos focais e no relato das observações das auxiliares de pesquisa, os dados foram organizados em duas partes. O conceito de cuidados à saúde, definido pelos auxiliares de enfermagem, compõe a primeira parte. Na segunda parte estão descritas as atividades de cuidados à saúde relatadas como desenvolvidas pelos mesmos.

Pode-se constatar, tanto por meio dos relatos das duas auxiliares de pesquisa quanto pela análise de suas observações escritas, que durante a realização dos grupos focais não ocorreram momentos de tensão ou discórdia, bem como qualquer acontecimento que pudesse influenciar as entrevistas, durante sua realização.

Foi relatado pelas auxiliares de pesquisa que o segundo grupo entrevistado se apresentou mais retraído do que o grupo anterior, sendo necessário estimulação constante para obtenção dos discursos. Acredita-se 
que tal fato pode estar relacionado ao atraso ocorrido para se iniciar o grupo, pois houve falta de energia na instituição estudada, o que dificultou e atrasou os afazeres matinais rotineiros destes profissionais. Como não havia possibilidade de novo agendamento, optou-se pela realização do grupo, mesmo assim.

\subsubsection{Definição de Cuidados à Saúde}

Os conceitos de cuidados à saúde foram agrupados em três categorias: atenção ao corpo biológico, apoio emocional e atividades de lazer.

Quadro 2 - Conceitos de cuidados à saúde dados pelos auxiliares de enfermagem que trabalham em uma instituição de longa permanência para idosos, São Paulo, março de 2008.

\begin{tabular}{|l|l|}
\hline Categorias & Idéias centrais \\
\hline Atenção ao corpo biológico & - Procedimentos: \\
& * higienização \\
& * alimentação/Hidratação \\
& * auxilio a deambulação \\
& * massagem de conforto \\
& * mudança de decúbito \\
& * administração de medicamentos \\
\hline Apoio emocional & - Atenção/ bom ouvinte \\
& - Promover relação familiar \\
& - Carinho \\
& - Amor \\
\hline Atividades de lazer & - Caminhada \\
& - Leitura \\
& - Artesanato \\
& - Canto \\
& - Festa \\
\hline
\end{tabular}


Verificou-se que na categoria "atenção ao corpo biológico" está centrada a maioria dos discursos dos entrevistados, isto é, o cuidado à saúde é definido como sendo apenas a realização de procedimentos técnicos, voltados para o cuidado com o corpo. Dos treze (13) auxiliares de enfermagem, sete (7) se utilizaram deste conceito.

Aqui estão alguns exemplos:

“(...) acho que cuidado com a saúde é fazer sua higiene, a boa alimentação, hidratá-los, a gente tá oferecendo bastante água, líquido."

“(...) banho, higiene pessoal, cuidados pessoais(...)"

“(...) acho que todos os horários certinho, em troca de fralda, massagem de conforto, mudança de decúbito (...) acho tudo isso sim, nos respectivos horários"

Segundo TEIXEIRA (2001), o cuidar na percepção da medicina moderna subordina o homem à técnica. Esta medicina, entre outros fatores, representa a civilização técnica e o poder da técnica.

PAl et al. (2006) afirmam que, apesar do conceito de saúde ir além do corpo físico, isto é, abordar as dimensões social, ambiental, político e econômico dos indivíduos, as práticas cotidianas de cuidados à saúde ainda estão centradas em função de diagnósticos e terapêuticas de corpos doentes.

Estas mesmas autoras pontuam que a enfermagem acompanha esta visão, uma vez que a grande maioria de suas atividades permanece dependente de determinações médicas, pois este é o protagonista da clínica do corpo. 
Para PIRES (2007), a enfermagem, em busca de reconhecimento profissional e, tentando se dissociar da imagem de santa, tem-se apoiado em atividades cientificas calcadas na técnica, determinando, aos profissionais, atitudes autoritárias, pouco políticas e excessivamente técnicas.

Através da análise histórica da evolução da enfermagem o ensino do cuidar, direcionado à enfermagem aparece nas ordens católicas femininas. Este ensino não era sistematizado, e sim baseado em virtudes pessoais como pobreza, caridade e disciplina. Os cuidados dispensados aos enfermos eram vistos como dádivas de Deus e do sentimento de sacrifício de quem os executava. A equipe de enfermagem deveria se comportar como religiosa e não como grupo profissional. A atividade não era caracterizada como profissional, pois as pessoas que a desenvolviam eram pobres e trabalhavam em troca de alimento, casa e proteção (MACHADO, 2002).

A prática de ensinar o cuidar de doentes foi realizada por médicos que tinham necessidade de contar com pessoas, um pouco mais preparadas, para auxiliar no seu trabalho. Essa demanda aumentou após as descobertas de Louis Pasteur que revolucionaram os conceitos de higiene e assepsia. Nos hospitais, as religiosas comandavam as equipes de auxiliares e de serviçais, e viam no cuidado um atributo de caridade e sacrifício, se recusando a assumir novas atribuições (OGUISSO, 2007b).

Em substituição às religiosas, os médicos buscaram pessoas que se submetessem a eles e, para isso recrutavam jovens modestas, que iriam exercer atividades limitadas, sempre secundárias às dos médicos e 
proibidas de tomar qualquer tipo de decisão ou iniciativa (OGUISSO, 2007b).

O trabalho da enfermagem, nesta época, começa a ser dividido, segundo tempo de experiência entre as matrons, que exerciam a chefia do serviço, e as sisters, que eram responsáveis pelos cuidados diretos aos enfermos. Iniciou-se a divisão social do trabalho de enfermagem, onde o fazer é caracterizado pela atividade manual e o saber pela atividade intelectual (MACHADO, 2002).

Esta dicotomia entre o saber e o fazer foi concretizada pela precursora da enfermagem moderna, Florence Nightingale.

O cuidado aos doentes e feridos e o treinamento de pessoal para exercer suas atividades já existiam antes de Florence, porém, sua personalidade forte, sua visão de prática e de organização deram à enfermagem os princípios técnicos e educacionais e a ética elevada para impulsionar a profissão, através da criação de oportunidades anteriormente impensáveis (OGUISSO, 2007b).

Segundo o modelo de ensino proposto por Florence, a escola formaria alunas para dois tipos de atividades: as que seriam responsáveis pelo comando, o poder e o saber da profissão e as que se incumbiriam do fazer (MACHADO, 2002).

Ainda hoje este modelo de fragmentação do cuidado - um detém o saber e manda e o outro, que possui a habilidade do fazer, executa fundamenta as ações desenvolvidas pelas equipes de enfermagem (PEDUZZI e ANSELMI, 2002).

Mesmo existindo como profissão de nível superior e haver 
conquistado um certo reconhecimento social, a enfermagem não era exercida por um quantitativo suficiente de pessoas que pudessem contemplar todas as tarefas necessárias para os cuidados aos clientes, principalmente os internados em hospitais. $\mathrm{Na}$ realidade, havia pessoas leigas trabalhando em hospitais, desempenhando tarefas de auxílio, porém não eram consideradas profissionais. Desta feita, foram criados cursos para capacitação destas pessoas, que passariam a ter status de profissional de nível não universitário, surgindo assim os auxiliares de enfermagem (SZNELWAR e UCHIDA, 2004).

Assim, estas mesmas autoras informam que a profissão de auxiliar de enfermagem surge para atender uma demanda hospitalar, direcionada a realização de procedimentos técnicos que englobam desde ações relativamente complexas, até as consideradas tecnicamente mais simples, como por exemplo, os cuidados com a higiene.

Infelizmente, a formação de nível médio de profissionais de enfermagem, através da grande maioria das escolas de qualificação profissão em enfermagem, permanece enfocando a assistência a pessoas que se encontram em ambiente hospitalar e não em outros ambientes como creches, escolas, centros dia, e instituições. Como está centrada na realização de procedimentos, as dimensões psicológicas, socioeconômicas e espirituais dos seres humanos, são postas em segundo plano.

Segundo WALDOW (1998), apesar dos docentes de instituições formadoras de profissionais de enfermagem, incluindo as de nível superior, discutirem sobre o cuidado holístico, informam aos alunos, na grande 
maioria das vezes, conteúdos e conceitos prontos, focados em patologias e procedimentos técnicos a serem desenvolvidos, limitando e fragmentando o cuidado a simples intervenções.

Questionados sobre as atividades que desenvolviam na casa. Todos informam que as suas atividades compreendem a realização de procedimentos técnicos.

"As atividades que eu exerço aqui nesta instituição é curativo, passagem de sonda e aplicação de injeção intramuscular, administração de medicação, cuidados gerais que uma profissional de enfermagem exerce".

“(...) realizo curativo, auxilio na alimentação dele e troca de fralda."

“(...) arrumação do leito do paciente, sinais vitais, (...) faço encaminhamento (...)"

“(...) auxilio nos cuidados gerais, na administração de medicação, administração de dieta, atendo a qualquer intercorrência (...)"

Verifica-se que a atuação dos auxiliares de enfermagem está focada nas necessidades humanas básicas classificadas enquanto necessidades psicobiologicas. Para HORTA (1979), o indivíduo, para ser saudável, necessita ter suas necessidades humanas básicas satisfeitas por completo, tanto as psicobiológicas quanto as psicossocias e as psicoespirituais.

Segundo esta mesma autora, estas necessidades são intimamente inter-relacionadas e não há como promover a satisfação das mesmas sem a 
aplicação do conceito holístico de ser humano "ele é um todo indivisível, não é a soma de suas partes" (pg.40).

MORAES (2002), em seu estudo sobre as necessidades e desejos de idosos asilados, através de entrevista com os mesmos, verificou que eles recebem atendimento de acordo com a visão da instituição sobre o que sejam suas necessidades, priorizando o atendimento daquelas de ordem biológica, tais como os cuidados com a alimentação, higiene e medicação.

Em estudo realizado com auxiliares de enfermagem de uma instituição hospitalar, quando questionados sobre qual deve ser a principal atividade de cuidados desenvolvida por eles, os mesmos responderam ser a execução de um procedimento técnico - a administração de medicação (PEDUZZI e ANSELMI, 2002).

Assim, os discursos dos auxiliares de enfermagem entrevistados refletem sua formação profissional, baseada na execução de procedimentos técnicos direcionada à cura e ao controle de doenças. Devemos considerar também que os cursos de formação de auxiliar de enfermagem, a exemplo de vários cursos de nível superior, não incluem em seu programa o cuidado à pessoa idosa.

O cuidado à saúde, visto como apoio emocional foi citado por quatro (4) auxiliares de enfermagem:

“(...) carinho, amor é que afeta muito a parte mental e cuidado de saúde, eu acho que é parte de atenção para os idosos (...)"

“(...) tem que ser muito bom ouvinte porque eles têm muitos talentos 
(...) tem que ser amigo, tem que ser mãe, tem que ser tudo, (...) isso ajuda muito na saúde deles."

“(...) para que ele leve a vida que Deus preparou para ele do melhor jeito possível, para que ele não se sinta tão inferior às pessoas (...)"

Do total de auxiliares de enfermagem, apenas dois (2) citaram a atividade de lazer como cuidado à saúde. Como exemplos têm-se as seguintes falas:

“(...) atividade física, o entretenimento, aqui tem muito canto, música, tem o pessoal do teatro que vem, eles ficam nossa, super eufóricos, as grandes festas (...) então para eles são fatos importantes (...) dá uma melhorada boa, aí no dia eles dormem melhor (...)"

“(..) acho que para cuidado da saúde é (...) fazer artesanato, fazerem alguma coisa para não ficar parado, a leitura (...)"

Os auxiliares de enfermagem que definiram cuidados à saúde além da perspectiva biológica de realização de procedimentos técnicos têm maior tempo de formação, acima de cinco (5) anos, trabalham na instituição há mais de três (3) anos e se encontram na faixa etária acima de quarenta (40) anos.

É interessante notar, que apesar de citarem o lazer como uma das dimensões do cuidado à saúde, parece estar fora do cuidado de enfermagem.

Nestas duas últimas categorias é possível visualizar um discurso onde 
o conceito de cuidado à saúde é concebido para além do bem-estar físico. As dimensões emocionais e sociais do ser humano são contempladas.

Contudo, tomando por base a Teoria das Necessidades Humanas Básicas de HORTA (1979), verifica-se que a definição de cuidados à saúde dada pelos auxiliares de enfermagem da pesquisa contempla apenas duas das três dimensões humanas de necessidades: as psicobiológicas e as psicossociais. A dimensão psicoespiritual, onde o ser humano busca "satisfação" relacionada à religiosidade, à ética ou à filosofia de vida, não foi citada.

Segundo AYRES (2004), o conceito de cuidado à saúde deve ir além do consagrado pelo senso comum, como o conjunto de procedimentos técnicos direcionados para o sucesso de um tratamento. Deve, sim, ser compreendido através de uma reflexão filosófica e uma atitude prática diante do significado que as ações de saúde expressam em diversas situações em que necessitam de ações terapêuticas.

Da mesma forma, WALDOW (2004) refere que o cuidado à saúde deve se expressar através da ação direcionada à pessoa e não centrada em patologias e técnicas. O ser humano deve ser enxergado sob todos seus aspectos: biológico, cultural, social e espiritual.

MARTIN e ANGELO (1998) descrevem o cuidado à saúde como o ato que busca proporcionar ao homem o equilíbrio entre corpo, mente, espírito e ambiente. 
4.2.2 Cuidados á Saúde Desenvolvidos pelos Auxiliares de Enfermagem

De acordo com as informações fornecidas pelos auxiliares de enfermagem é possível categorizar as falas em dois grupos: os que relacionam os cuidados à saúde desenvolvidos como a realização de ações de atenção ao corpo biológico e os que caracterizam estes cuidados como a realização de ações de apoio emocional.

Quadro 3 - Atividades de cuidados à saúde relatadas como desenvolvidas pelos auxiliares de enfermagem que trabalham em uma instituição de longa permanência para idosos, São Paulo, março de 2008.

\begin{tabular}{|l|l|}
\hline Categorias & Idéias centrais \\
\hline Atenção ao corpo biológico & - Procedimentos \\
& * higienização \\
& * alimentação/Hidratação \\
& * auxilio a deambulação \\
& * administração de medicamentos \\
& * mudança de decúbito \\
& * verificação de sinais vitais \\
& * ações de primeiros socorros \\
& * acompanhamento do idoso em \\
atendimento fora da instituição & * troca de roupa \\
\hline Apoio emocional & - Toque \\
& - Atenção \\
& - Amor \\
& - Carinho \\
\hline
\end{tabular}

A maioria dos sujeitos identifica os procedimentos técnicos como sendo os principais cuidados à saúde desenvolvidos por eles.

“(...) é administrar as medicações via oral, aferir P.A., atender uma emergência, é fazer um curativo (...) todos os cuidados de enfermagem do dia-a-dia (...)" 
Cabe colocar que, após a discussão do conceito de cuidado à saúde, os mesmo quatro (4) auxiliares de enfermagem que definiram cuidados à saúde além da dimensão biológica, anteriormente, informaram executar ações de apoio emocional como atividades direcionadas a cuidados à saúde. Seguem-se alguns depoimentos:

“(...) uma atenção mínima que você dá ao idoso ele já se sente é, maravilhoso, alegre ...se ele te chama e você pode passar e pelo menos colocar a mão, pegar na mão dele (...)"

“(...) a hora que você tem, que você tira para brincar com eles, conversando para tirar eles daquela monotonia né (...)"

“(...) então a gente tenta talvez brincar, sabe, com um pouco mais, com cada um entendeu, porque à vezes é difícil, porque nós somos também em poucas aqui na instituição (...)"

“(...) eles gostam muito de carinho, muito que paparica, nossa como gostam, podia ter uma só para paparicar (...)"

Estas atividades de apoio emocional, segundo BRACKERS et al. (2006), pressupõem o envolvimento das pessoas, promovendo uma relação de empatia e troca entre os envolvidos. Desta feita, o cuidado à saúde, realizado através do cuidado de enfermagem, vai muito além da realização de uma técnica.

Em estudo realizado sobre a humanização da atenção à saúde, visualiza-se a conceituação desta como um resgate do atendimento focado 
no indivíduo e não em procedimentos técnicos. O ser humano, aqui, é visto em sua singularidade, tendo necessidades específicas, onde seus valores, crenças e formas de viver são respeitados (FORTES, 2004).

Além disso, o conceito de humanização da assistência inclui a atenção ao ambiente de trabalho, a motivação da equipe de cuidados, a atenção aos aspectos éticos envolvidos nos cuidados, a destreza técnica e o auxílio na manutenção do equilíbrio físico-emocional (OLIVEIRA e KRUSE, 2006).

Os sujeitos deste estudo informam, em seus discursos, que não dispõem de muito tempo para este tipo de cuidado, pois são em número reduzido de profissionais de enfermagem na instituição e não é sempre que este tipo de cuidado é possível de ser ofertado.

Tal situação se dá, crê-se, devido às características da instituição estudada: filantrópica, cem por cento gratuita, sem auxílio governamental, com diversas dificuldades materiais e de recursos humanos. Desta forma, a instituição direciona suas ações e espera dos profissionais auxiliares de enfermagem, a execução de procedimentos de forma a oferecer atendimento básico aos residentes, centrado na satisfação das necessidades biológicas, como moradia, alimento, higiene vestuário, medicação, entre outros. 


\section{CONCLUSÃO}

Os treze (13) profissionais auxiliares de enfermagem que compõem a equipe de enfermagem entrevista neste estudo, em sua grande maioria, define cuidados à saúde como a realização de procedimentos técnicos - atenção ao corpo biológico - direcionados à satisfação das necessidades biológicos dos idosos residentes em uma instituição de longa permanência. Um número pequeno (menos de um terço) de profissionais conceitua cuidados à saúde como a realização, também, de atividades de apoio emocional e de lazer.

Quando levados a relacionar o conceito de cuidado à saúde anteriormente definido por eles com as atividades desenvolvidas na sua prática assistencial o resultado se mantém, excluindo-se as ações de atividades de lazer que como dito anteriormente, fazem parte das atividades desenvolvidas por outras pessoas. 


\section{CONSIDERAÇÕES FINAIS}

A pesquisa possibilitou constatar que as ações relativas ao cuidado à saúde não seguem o preconizado enquanto estratégia de atendimento aos idosos. Estes devem ser respeitados e vistos enquanto seres humanos, proprietários de uma história de vida que reflete suas crenças, valores, condições sociais e ambientais em que cresceram, portanto, seres completos e complexos e não apenas um ser biológico, composto por um corpo que necessita de auxílio.

É sabido que as famílias e os próprios idosos depositam, nas instituições de longa permanência, grande responsabilidade, como a proteção, o cuidado, o lazer e a integração social.

Porém, para que todas estas metas sejam alcançadas, é necessário que a instituição tenha recursos materiais, físicos, humanos e financeiros em quantidade suficiente e qualidade adequada, proporcionalmente às necessidades expressas por seus residentes. Infelizmente, esta não é a realidade da imensa maioria das instituições existentes.

Ao se analisar as características da instituição estudada, verifica-se que a mesma sobrevive heroicamente, sem subsídio ou atenção de qualquer órgão governamental. Ela possui como missão, o atendimento integral aos idosos desamparados e que não possuem condições mínimas de subsistência, além de ser responsável, de forma quase exclusiva, pelo bemestar físico, mental, social e espiritual dos que lá residem, porém, encontra- 
se marginalizada, como a grande maioria de instituições de longa permanência para idosos em nosso país.

Desta feita, faz-se necessário a discussão e criação de políticas públicas voltadas para ao amparo a idosos que residem em instituições de longa permanência para idosos, principalmente as filantrópicas e, em particular, as cem por cento gratuitas.

Figura-se necessário, também, um repensar sobre as práticas assistenciais das equipes de enfermagem em instituições de longa permanência para idosos, pois esta é a principal responsável pela execução dos cuidados diretos à saúde dessas pessoas. Também há necessidade de se rever o conteúdo dos cursos de formação e qualificação profissional voltados a estes profissionais.

Torna-se necessário a inclusão de conteúdos que discutam e definam conceito de cuidados à saúde através de uma perspectiva holística e humanizada. A formação deve se voltar também para o preparo desses profissionais para os diversos serviços em que esses profissionais podem vir a atuar, além dos hospitais; e considerando o rápido processo de envelhecimento populacional brasileiro, conteúdos sobre o cuidado a pessoas idosas, suas peculiaridades e potencialidades também devem ser incluídos. O idoso deve ser visto como um indivíduo que apresenta necessidades diferentes dos demais adultos.

Necessita-se fomentar a implantação de cursos de qualificação de auxiliares de enfermagem na área gerontológica, bem como ampliar a divulgação dos existentes, visando estimular a formação de profissionais que 
aplicam conhecimentos e conceitos sobre o envelhecimento em sua dinâmica assistencial, tornando-se capazes de reconhecer e atender as necessidades de cuidados à saúde dos idosos do processo de envelhecimento.

Ressalta-se que o presente estudo não teve a intenção de esgotar o assunto referente aos cuidados à saúde que são prestados pela equipe de enfermagem aos idosos institucionalizados. Outros estudos e reflexões deverão ser realizados para validar os dados levantados e enriquecer o debate sobre o assunto abordado.

É fundamental que as instituições de longa permanência para idosos busquem qualificar sua equipe de cuidados para que esta possa atender, satisfatoriamente, aos idosos que lá residem. Desta forma, deve ser considerada uma proposta de criação de uma comissão responsável pelo desenvolvimento de ações de educação continuada voltadas aos auxiliares de enfermagem que trabalham nas instituições que compõem o Fórum de Instituições de Longa Permanência para Idosos. Esta proposta de realização de ações conjuntas de educação continuada pode ser considerada mais uma forma de fortalecimento do Fórum enquanto grupo na busca da qualificação dos cuidados prestados, racionalizando os poucos recursos que as instituições filantrópicas têm.

O investimento na educação permanente de profissionais que prestam ações voltadas aos cuidados de saúde de idosos residentes em instituições de longa permanência reflete diretamente na qualidade de vida dos idosos. 


\section{REFERÊNCIAS}

AGÊNCIA NACIONAL DE VIGILÂNCIA SANITÁRIA (ANVISA). Resolução da Diretoria Colegiada $n^{0}$ 283, de 26 de setembro de 2005. Aprova o regulamento técnico que define normas de funcionamento para as instituições de longa permanência para idosos. Diário Oficial da União, Brasília, DF, 27 set. 2005. p. 58-59.

ALMEIDA FILHO, N. O conceito de saúde: ponto-cego da epidemiologia? Rev. Bras. Epidem. São Paulo, v. 3, n. 1, p. 3-20, 2000.

ASCHIDAMINI, I.M., SAUPE, R. Grupo focal - estratégia metodológica qualitativa: em ensaio teórico. Cogitare Enf., Curitiba, v. 9, n. 1, p. 9-14, jun. 2004.

AYRES, J.R. de C. M. Cuidado e reconstrução das práticas de saúde. Interface, Botucatu, v. 8, n. 14, p. 73-92, fev. 2004.

BACKERS, D. S., et al. Concepção de cuidado: uma análise das teses apresentadas para um programa de pós-graduação em enfermagem. Texto Contexto Enf, Florianópolis, v. 15 (esp), p. 71-8, 2006

BAHURY, A.M.N. Idosos em asilos: o processo de transição da vida privada 
para a vida institucional. 1996, 162p. Dissertação (Mestrado em Sociologia) - Instituto Universitário do Rio de Janeiro, Rio de Janeiro.

BALTES, M. M. et al. Maintenance and rehabilitation of independence in old age: an intervention program for staff. Psycology and Aging, Arlington, v. 9, n. 2, p. 179-88, jun. 1994.

BALTES, M.M., SILVERBERG, S. A dinâmica dependência-autonomia no curso da vida. In: NERI, A.L. (Org.). Psicologia do envelhecimento. Campinas: Papirus, 1995. p.73-110.

BARDIN, L. Análise de conteúdo, Lisboa, Edição 70, 1977.

BERGER, L., MAILLOUX-POIRIER, D. Pessoas idosas: uma abordagem global. Lisboa: Lusodidacta, 1995, p. 1-9.

BOECHAT, N. S. Institucionalização. Arqu. Geriat. Geront., Rio de Janeiro, p. 58-61, maio 1996.

BORN, T., BOECHAT, N.S. A qualidade dos cuidados ao idoso institucionalizado. In: FREITAS, E.V. et al. Tratado de geriatria e gerontologia. Rio de Janeiro: Guanabara Koogan, 2002. p. 768-77

BRASIL. Decreto № 7.498, de 25 de junho de 1986. Dispõe sobre a 
regulamentação do exercício da Enfermagem e dá outras providências. Diário Oficial da União, Brasília, 26 jun. 1986, p. 9273-75.

. Constituição (1988). Constituição da República Federativa do Brasil. Brasília, DF: Senado, 1988.

. Lei $n^{\circ}$ 8.142, de 28 de dezembro de 1990. Dispõe sobre a participação da comunidade na gestão do Sistema Único de Saúde (SUS) e sobre as transferências intergovernamentais de recursos financeiros na área da saúde e dá outras providências. Diário Oficial da União, Brasília, DF, 31 dez. 1990 , p. 025694.

. Lei $n^{\circ}$ 8.842, de 4 de janeiro de 1994. Dispões sobre a política nacional do idoso, cria o Conselho Nacional do idoso e dá outras providências. Diário Oficial da União, Brasília, DF, 5 jan. 1994. p. 77

. Lei ํㅜ 10.741 , de $1^{\circ}$ de outubro de 2003. Dispõe sobre o Estatuto do Idoso e dá outras providências. Diário Oficial da União. Brasília, DF, 3 out. 2003. p. 1-6.

BRITO, F. C., RAMOS, L. R. Serviços de atenção à saúde do idoso. In: PAPALEO NETTO, M. (Org.). Gerontologia: a velhice e o envelhecimento em visão globalizada. São Paulo: Atheneu, 2002. p. 394-402 
BRUM, A.K. et al. O enfermeiro como instrumento de ação no cuidar do idoso. Rev. Latino-Am. Enfermagem, Ribeirão Preto, v. 13, n. 6, p. 101926, nov./dez. 2005.

BUJDOSO, Y. L. V. et al. A academia e a divisão social do trabalho na enfermagem no setor público: aprofundamento ou superação? Ciênc. Saúde Coletiva, Rio de Janeiro, v. 12, n. 5, p. 1363 - 74, set./out. 2007.

CALDAS, C. P. Envelhecimento com dependência: responsabilidades e demandas da família. Cad. Saúde Pública. São Paulo, v. 19, n. 3, p. 733-81, maio 2003.

CAMARANO. A. A. et.al. Presidência da República, Subsecretaria de Direitos Humanos. Idosos brasileiros: indicadores de condições de vida e de acompanhamento de políticas. Brasília, 2005.

CHAIMOWICZ, F. A saúde dos idosos brasileiros às vésperas do século XXI: problemas, projeções e alternativas. Rev. Saúde Pública. São Paulo, v. 31, n. 2, p. 184-200, abr. 1997.

CHAIMOWICZ, F., GRECO, D. B. Dinâmica da institucionalização de idosos em Belo Horizonte, Brasil. Rev. Saúde Pública. São Paulo, v. 33, n. 5, p. 454-60, out. 1999. 
COELHO, C. P. e col. Escola de Enfermagem Anna Nery: sua história, nossas memórias. Rio de Janeiro: Cultura Médica, 1997.

COLLINS, C. et al. Interviewer training and supervision. Nurs Res. Michigan, v. 37, n.2, p. 122-24, mar/apr1988.

CONSELHO NACIONAL DE SAÚDE. Resolução ํo 196, de 10 de outubro de 1996. Diretrizes e normas regulamentadoras de pesquisa em seres humanos. Brasília: Ministério da Saúde, 1996.

CORETELLETTI, I. A. e col. Idosos asilados: um estudo gerontológico. Caxias do Sul: Edusc/Edipucrs, 2004.

DALL'AGNOL, C. M., TRENCH, M. H. Grupos focais como estratégia metodológica em pesquisa na enfermagem. Rev. Gauch. Enf, Porto Alegre, v. 20, n.1, p. 5-25, jan. 1999.

DALLARI, S. G., FORTES, P. A. de C. Direito sanitário: inovações teóricas e novo campo de trabalho. In: FLEURY, S. M. T. (Org.). Saúde e democracia: a luta do CEBES. São Paulo: Lemos Editora, 1997, p. 187-99.

DUARTE, Y. A. de O desempenho funcional e demandas assistenciais. In: LEBRÃO, M., DUARTE, Y. A. de (Orgs). SABE - Saúde, Bem-estar e Envelhecimento. O Projeto SABE no município de São Paulo: uma 
abordagem inicial. Brasília: Organização Pan-Americana da Saúde, 2003, p. 184-200.

DUARTE, Y. A. de O., LEBRÃO, M. L. O cuidado gerontológico: um repensar sobre a assistência em gerontologia. In: PESSINI, L., BARCHIFONTAINE, C de P. de. (Org.). Bioética e longevidade humana. São Paulo: Loyola, 2006, p. 467-84.

FORTES, P. A. de C. Ética, direitos dos usuários e políticas de humanização da atenção à saúde. Saúde Soc., São Paulo, v. 13, n. 3, p. 30-5, set/dez. 2004.

GEORGE, J. B. Madeleine M. Leininger. In: GEORGE, J.B. e col. Teorias de enfermagem: os fundamentos à prática profissional. 4 ed. Porto Alegre: Artes Médicas, 2000. p. 297- 309.

GOFFMAN. E. Manicômios, prisões e conventos. 7 ed. 2 reimpressão. São Paulo: Perspectiva, 2005.

HORTA, W. de A. Processo de enfermagem. São Paulo: EPU, 1979.

IBGE. Instituto Brasileiro de Geografia e Estatística. Perfil dos idosos responsáveis pelos domicílios no Brasil, 2000. Rio de Janeiro, 2002. Disponível em: 
< http://www.ibge.gov.br/home/estatistica/populacao/perfilidoso/perfidosos200 $\underline{0 . p d f}>$. Acesso em 22 out. 2007.

IERVOLINO, S.A., PELICIONI, M. C. F. A utilização do grupo focal como metodologia qualitativa na promoção da saúde. Rev. Esc. Enferm. USP, São Paulo, v. 35, n. 2, p. 11-21, jun. 2001.

KANE, R. A., KANE, R.L. Long-term care: principles, programs, and policies. New York: Springer, 1987.

LOBIONDO-WOOD, G., HABER, J. Métodos, avaliação crítica e utilização. 4 ed., Rio de Janeiro: Guanabara Koogan, 2001, p. 176.

LONGARAY, V. K., et al. Processo de enfermagem: reflexões de auxiliares e técnicos. Texto Contexto Enf, Florianópolis, v. 17, n. 1, p. 150-7, 2008.

LOUZÃ NETO, M.R., et al. O idoso, as instituições totais e a institucionalização. Rev. Paul. Hosp., São Paulo, v. 34, n.7, p. 135-43, jul/ago/set. 1986.

MACHADO, W. C. A. reflexão sobre a prática profissional do enfermeiro. In: GEOVANINI, T. et al. História da enfermagem: versões e interpretações. 2 ed. Rio de Janeiro: Revinter, 2002, p. 255-334. 
MAFFIOLETTI, V. L. R. et al. Os sentidos e destinos do cuidar na preparação dos cuidadores de idoso. Ciênc. Saúde Coletiva, Rio de Janeiro, v. 11, n. 4, p. 1085-95, out/dez. 2006

MARTIN, V. B., ANGELO, M. Significado do conceito saúde na perspectiva de famílias em situação de risco pessoal e social. Rev. Latino-Am. Enfermagem, Ribeirão Preto, v. 6, n. 5, p. 45-51, dez. 1998.

MARTINELI, M. L. O uso de abordagens qualitativas na pesquisa em serviço social. Cadernos do Núcleo de Estudos e Pesquisa sobre Identidade PUC/SP, São Paulo, n. 1, p. 11-8, 1994.

MARTINEZ, S. H.L. O significado do cuidado para quem cuida do idoso em uma instituição asilar. 2003, 146p. Dissertação (Mestrado em Enfermagem) - Escola Paulista de Medicina - Universidade Federal de São Paulo, São Paulo.

MEIER, M. J., KUDLOWIEZ, S. Grupo focal: uma experiência singular. Texto Contexto Enf, Florianópolis, v. 12, n. 3, p. 394-9, 2003.

MELO, C. A divisão social do trabalho de enfermagem. São Paulo: Cortez, 1986.

MINAYO, M.C. de S., SANCHES, O. Quantitativo-qualitativo: oposição ou 
complementaridade? Cad. Saúde Pública, São Paulo, v. 9, n. 3, p. 237-48, jul/set. 1993.

MINISTÉRIO DA SAÚDE. Gabinete do Ministro. Portaria nㅜ‥528, de 19 de outubro de 2006. Aprova a política nacional de saúde da pessoa idosa. Diário Oficial da União, Brasília, DF, 19 out. 2006. p.142-45a.

MINISTÉRIO DA SAÚDE. Gabinete do Ministro. Portaria ํㅜ 675, de 30 de março de 2006. Aprova a Carta dos direitos dos usuários de saúde, que consolida os direitos e deveres do exercício da cidadania na saúde em todo o país. Diário Oficial da União, Brasília, DF, 30 mar. 2006. p. 131-32b.

MORAES, I. de A. L. A saúde do idoso no contexto asilar: implicações da institucionalização e as ações interventivas de enfermagem. 2002,115p. Dissertação (Mestrado em Enfermagem) - Faculdade de Enfermagem Universidade do Estado do Rio de Janeiro, Rio de Janeiro.

MORAES, I. de A. L., DUARTE, M. J. R. S. Desinstitucionalizando o cuidar: uma reflexão voltada para as necessidades do idoso asilado. Rev. Enferm. UERJ, Rio de Janeiro, v. 10, n. 3, p. 237-42, set/dez. 2002.

NOGUEIRA-MARTINS, M. C. F., BÓGUS, C. M. Considerações sobre a metodologia qualitativa como recurso para o estudo das ações de humanização em saúde. Saúde Soc., São Paulo, v. 13, n. 3, p. 44-57, 
set/dez. 2004.

NOVAES, M. R. V. A busca do consenso sobre as condições de autonomia e dependência de idosos residentes em instituições de longa permanência: uma metodologia de trabalho para a equipe de cuidados. 2005, 239p. Tese (Doutorado em Saúde Pública) - Faculdade de Saúde Pública, Universidade de São Paulo, São Paulo.

OGUISSO, T. As origens da prática do cuidar. In: (Org). Trajetória histórica e legal da enfermagem. 2 ed. ampl. Barueri: Manole, 2007 , p. $3-29 a$.

OGUISSO, T. Florence Nightingale. In: (Org). Trajetória histórica e legal da enfermagem. 2 ed. ampl. Barueri: Manole, 2007, p. 58 $-97 b$.

OLIVEIRA, C. P. de, KRUSE, M. H. L. A humanização e seus múltiplos discursos - análise a partir da REBEn. Rev. Bras. Enferm., Brasília, v. 59, n. 1, p. 78-83, jan./fev. 2006.

OREM, D. E. Nursing: concepts of pratice. 4 ed. Sant Louis: Mosby, 1991.

ORGANIZAÇÃO MUNDIAL DE SAÚDE. Carta de Ottawa para La Promocion de La Salud. Ottawa, 1986. 
ORGANIZAÇÃO PANAMERICANA DE SAÚDE. Relatório final da vigésima quinta Conferência Sanitária Panamericana. Washington, 1998a.

ORGANIZAÇÃO PANAMERICANA DE SAÚDE. Salud de las personas de edad: envejecimiento y salud: un cambio de paradigma. Washington, 1998b.

PAI, D. D., et al. O enfermeiro como ser sócio-político; refletindo a visibilidade da profissão do cuidado. Acta Paul. Enferm. São Paulo, v. 19, n. 1, p. 82-7, mar. 2006.

PAPALEO NETTO, M., PONTE, J.R. Envelhecimento: desafio na transição do século. In: PAPALEO NETTO, M. (Org.). Gerontologia. São Paulo: Atheneu, 1997. p. 3-12.

PASCHOAL, S. M. P. Desafios da longevidade: qualidade de vida. In: PESSINI, L., BARCHIFONTAINE, C de P. de. (Org.). Bioética e longevidade humana. São Paulo: Loyola, 2006, p. 329-36.

PAVARINI, S. C. I. Dependência comportamental na velhice: uma análise do cuidado prestado ao idoso institucionalizado. 1996. 230p. Tese (Doutorado em Educação) - Faculdade de Educação - Universidade Federal de Campinas, Campinas. 
PAVARINI, S. C. I., NERI, A.L. Compreendendo dependência, independência e autonomia no contexto domiciliar: conceitos, atitudes e comportamentos. In: DUARTE, Y. A. O., DIOGO, M. J. D. Atendimento domiciliar: um enfoque gerontológico. São Paulo: Atheneu, 2000, p. 69-82.

PEDUZZI, M., ANSELMI, M. L. O processo de trabalho de enfermagem: a cisão entre planejamento e execução do cuidado. Rev. Bras. Enferm., Brasília, v. 55, n. 4, p. 392-8, jul./ago. 2002.

PIRES, M. R. G. M. Pela reconstrução dos mitos da enfermagem a partir da qualidade emancipatória do cuidado. Rev. Esc. Enferm. USP, São Paulo, v. 41, n. 4, p. 717-23, jul./ago. 2007.

RAMOS, L. R., et. al. Perfil do idoso em área metropolitana na região sudeste do Brasil. Rev. Saúde Pública, São Paulo, v.27, n. 2, p. 87-94, abr. 1993.

REIS, P. O., CEOLIM, M.F. O significado atribuído a "ser idoso" por trabalhadores de instituições de longa permanência. Rev. Esc. Enferm. USP, São Paulo, v. 41, n. 1, p. 57-64, mar. 2007.

REZENDE, J.M. Institucionalização do idoso. Linguagem Médica. 2002. Disponível: em $\quad<$ http://usuarios.cultura.com.br/jmrezende/idoso.htm>. Acesso em: 23 out 2007. 
ROCHA, S. M. M., ALMEIDA, M. C. P. de. O processo de trabalho da enfermagem em saúde coletiva e a interdisciplinaridade. Rev. Latino-Am. Enfermagem, Ribeirão Preto, v. 8, n. 6, p. 96-101, dez. 2000.

ROSA, A. da S. et al. O processo saúde-doença-cuidado e a população em situação de rua. Rev. Latino- Am. Enfermagem, Ribeirão Preto, v. 13, n. 4, p. 576-82, jul/ago. 2005.

SÁ, S. P. C., FERREIRA, M. da A. Cuidados fundamentais na arte de cuidar do idoso: uma questão para a enfermagem. Esc. Anna Nery Rev. Enferm., Rio de Janeiro, v. 8, n. 1, p. 46-52, abr. 2004.

SALDANHA, A. L. Quando é preciso escolher uma instituição geriátrica: instrumentos para avaliação da qualidade dos serviços. In: SALDANHA, A. L., CALDAS, C. P. Saúde do idoso: a arte de cuidar. São Paulo: Interciência, 2004, p. 27-43.

SEGRE, M., FERRAZ, F.C. O conceito de saúde. Rev. Saúde Pública, São Paulo, v. 31 n. 5, p. 538-42, out. 1997.

SZNELWAR, L., UCHIDA, S. Ser auxiliar de enfermagem: um olhar da psicodinâmica do trabalho. Rev. Produção, São Paulo, v. 14 n. 3, p. 87-98, set/dez. 2004. 
TEIXEIRA, E. Travessias, redes e nós: complexidade do cuidar cotidiano de saúde entre ribeirinhos. Umarizal:Grafia Gráfica, 2001. p. 25-47.

TEIXEIRA, I. N. A. O. Percepções de profissionais de saúde sobre duas definições de fragilidade no idoso. Ciênc. Saúde Coletiva, Rio de Janeiro, v. 13, n. 4, p. 1181 - 6, jul./agost. 2008.

WALDOW, V. R. Cogitando sobre o cuidado humano. Cogitare Enferm, Curitiba, v. 3, n. 2, p. 7-10. 1998.

WALDOW, V. R. O cuidado na saúde: as relações entre o eu, o outro e o cosmos. Petrópolis: Vozes, 2004.

WEINERT, C., BURMAN, M. Nurturing longitudinal samples. West J Nurs Res, Missouri, v.18, N.3, p. $360-4, \quad$ jun. 1996. 


\section{Questionário}

1Nome:

2 - Idade: anos. 3-Sexo: ( ) masculino ( ) feminino

4 - Função exercida na instituição: ( ) Técnico de Enfermagem

( ) Auxiliar de Enfermagem

5 - Período em que trabalha na instituição: ( ) manhã ( ) tarde

( ) noite

6 - Tempo de formação: anos

7 - Trabalha em outro local além deste: ( ) não ( ) sim Onde:

8 - Quais foram os dois últimos vínculos profissionais que você teve:
a) Local: ( ) hospital
( ) ambulatório
( ) outra ILPI

( ) outros. Especificar função:

b) Local: ( ) hospital ( ) ambulatório ( ) outra ILPI

( ) outros. Especificar função: 


\section{Termo de Compromisso da Pesquisadora}

Eu, Mirela Bertoli Passador, pesquisadora responsável pelo projeto intitulado "Identificação dos cuidados à saúde prestados, pela equipe de enfermagem, aos idosos residentes em uma instituição de longa permanência filantrópica do município de São Paulo", assumo a responsabilidade de comunicar imediatamente à instituição toda e qualquer complicação ocorrida durante a realização do referido projeto que ponha em risco a instituição ou seus residentes. Cumprirei a Resolução CNS 196/96 e suas complementares, que tratam da pesquisa envolvendo seres humanos.

Comprometo-me, em hipótese alguma, identificar a instituição pesquisada, bem como seus colaboradores, além de não tecer comentário algum, com outras pessoas ou instituições.

Responsabilizo-me, outrossim, a apresentar oficialmente e primeiramente a todos os colaborados desta instituição, os resultados obtidos nesta pesquisa.

São Paulo, de de

Pesquisadora: Mirela Bertoli Passador

$R G: 23.283 .322-9$ 


\section{Termo de Compromisso da Instituição}

$\mathrm{Eu}, \quad \operatorname{Sr}(\mathrm{a})$

responsável técnico da instituição

declaro estar ciente e de acordo com a realização da pesquisa intitulada "Identificação dos cuidados a saúde prestados, pela equipe de enfermagem, aos idosos residentes em uma instituição de longa permanência filantrópica do município de São Paulo", nas dependências desta instituição. Declaro ainda que conheço a Resolução CNS 196/96, e suas complementares, sobre a pesquisa envolvendo seres humanos e que farei com que a mesma seja respeitada.

São Paulo, de de

Nome:

RG: 


\section{Termo de Consentimento Livre e Esclarecido (destinado aos profissionais de enfermagem da instituição)}

\section{I- Dados de identificação do sujeito da pesquisa}

Nome:

Documento de identidade $\mathrm{n}$ ㅇ: Sexo: ( ) M ( ) F

Data de Nascimento: $1 \quad 1$

Endereço: Número: Complemento:

Bairro: Cidade:

CEP: Telefone:

\section{II - Dados sobre a Pesquisa}

- Título do Protocolo de Pesquisa: "Identificação dos cuidados à saúde prestados, pela equipe de enfermagem, aos idosos residentes em uma instituição de longa permanência filantrópica do município de São Paulo".

- Pesquisadora: Mirela Bertoli Passador

- Documento de identidade no: 23.283.322-9 Sexo: feminino

- Carga/Função: Aluna de Pós-Graduação - Mestrado

- Departamento de Práticas de Saúde Pública da Faculdade de Saúde Pública da Universidade de São Paulo

- Avaliação de Risco da Pesquisa: Sem risco (X)

- Duração da Pesquisa: 9 meses

\section{III - Registro das explicações do pesquisador ao sujeito da pesquisa}

O envelhecimento humano provoca alterações fisiológicas que podem desencadear incapacidades funcionais e problemas de saúde, tornando 
necessária a intervenção de outras pessoas para garantir o bem estar do idoso. Este estudo tem como objetivos identificar os cuidados à saúde prestados, bem como o significado atribuído ao termo cuidado à saúde, pela equipe de enfermagem de uma instituição de longa permanência filantrópica do município de São Paulo.

Para coleta de dados, será realizada uma discussão em grupo, conhecida como grupo focal, com duração entre uma hora e uma hora e meia, onde serão abordados os cuidados à saúde prestados e a compreensão que os participantes têm sobre cuidados à saúde. Esta discussão será gravada e transcrita para a análise. Também serão solicitadas algumas informações como sexo, idade, tempo de trabalho na ILPI para a caracterização do grupo como um todo.

As informações obtidas serão utilizadas apenas para a realização desta pesquisa e o (a) senhor (a), bem como a instituição onde trabalha não serão identificados. Os resultados serão divulgados através da dissertação de mestrado, apresentados em eventos e artigos científicos. Garantimos o anonimato de sua pessoa, bem como o da instituição. As gravações de voz, realizadas durante as sessões e as transcrições permanecerão sob a guarda exclusiva da pesquisadora.

Esclarecemos que a sua participação é voluntária e não implica risco à sua integridade física ou moral. $\mathrm{O}$ (a) senhor (a) poderá solicitar esclarecimentos à pessoa responsável pelo grupo focal ou a qualquer hora com a pesquisadora pelo telefone (11) 9659-5672 ou pelo e-mail: mirelapassador@usp.br, ou junto ao Comitê de Ética em Pesquisa da Faculdade de Saúde Pública da USP, pelo telefone 3061-7797 ou no endereço, Av. Dr. Arnaldo 715, ou pelo e-mail: coep@fsp.usp.br.

O (a) senhor (a) poderá solicitar seu desligamento da pesquisa a qualquer momento, sem que haja qualquer prejuízo para sua pessoa ou instituição, bastando para isso entrar em contato com a pesquisadora ou com o Comitê de Ética em Pesquisa pelos telefones ou e-mail citados anteriormente. 


\section{IV - Consentimento Pós-Esclarecido}

Declaro que, após convenientemente esclarecido pelo pesquisador e ter entendido o que me foi explicado, consinto em participar do presente Protocolo de Pesquisa.

São Paulo, de de

Sujeito da Pesquisa

Nome:

$\mathrm{RG}$ :
Pesquisadora Responsável

Mirela Bertoli Passador

RG: 23.283.322-9 
Protocolo

Projeto de Pesquisa

Pesquisador(a)
1704

IDENTIFICAÇÃO DOS CUIDADOS DE SAÚDE, PRESTADOS PELA EQUIPE DE ENFERMAGEM, AOS IDOSOS RESIDENTES EM UMA INSTITUICCÃO DE LONGA PERMANÊNCIA FILANTRÓPICA DO MUNICÍPIO DE SÃO PAULO

Mirela Bertoli Passador

Prezado(a) Orientador(a),

o Comitê de Ética em Pesquisa da Faculdade de Saúde Pública da Universidade de São Paulo - COEP analisou de acordo com os requisitos da Resolução CNS/196/96 e suas complementares, o protocolo de pesquisa acima intitulado e o considerou APROVADO "adreferendum".

Recomenda-se a(o) pesquisador(a) que encaminhe 2 (dois) CD's atualizado, contendo todas as alteraçōes feitas no decorrer do projeto, incluindo-se os anexos, em formato não editável.

Cabe lembrar que conforme Resoluçāo CNS/196/96 são deveres do (a) pesquisador (a):

1. Comunicar, de imediato, qualquer alteração no projeto e aguardar manifestaçāo deste CEP (Comitê de Ética em Pesquisa), para dar continuidade à pesquisa;

2. Manter sob sua guarda e em local seguro, pelo prazo, de 5 (cinco) anos, os dados da pesquisa, contendo fichas individuais a todos os demais documentos recomendados pelo CEP, no caso eventual auditoria;

3. Comunicar, formalmente a este Comitê, quando do encerramento deste projeto:

4. Elaborar e apresentar relatórios parciais e finais;

5. Justificar, perante o CEP, interrupção do projeto ou a não publicação dos resultados.

Atenciosamente,

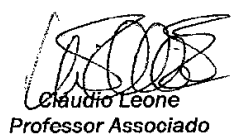

Professor Associado

Coordenador do Comitê de Ética em Pesquisa - FSP/COEP

Itm. ${ }^{a} \mathrm{Sr} .^{\mathrm{a}}$

Prof. ${ }^{a}$ Dr. ${ }^{a}$ HELENA AKEMI WADA WATANABE

DEPARTAMENTO DE PRÁTICA DE SAÜDE PÚBLICA

Av Dr Arnaldo, 715 - Assessoria Acadêmica - CEP: 01246-904 - São Paulo - SP Telefones: (55-11) 3061-7779/7742 e-mail: coep@fsp.usp.br site www.fsp.usp.br 
Possui graduaçāo em Enfermagem (1982), Habilitaçăo em Enfermagem de Saúde Pública e

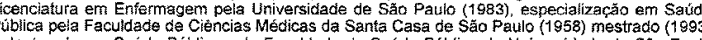

doutorado em Saúde Pública pela Faculdade de Saúde Pública da Universidade de Săo Paul

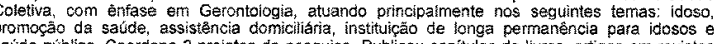

aude pública. Coordena 2 projetos de pesquisa. Publicou capitulos de livros, artigos em revistas

Geriatria e Gerontologia apresentando trabaihos foi membro da comissân orranizaciora de atigun

desses eventos. For vice-coordenadora e atualmente émembro do comite de Etica em Fesquisa da Facuidade de Saúde Pública da Universidade de Sáo Paulo.
(Texto intormato pelo autor)

Última atualizaçăo do curriculo em 18/06/2008

Endereço para acessar este $\mathrm{CV}$.

hitp: /flattes. cnpq.br/929128475380438

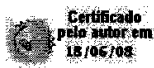

\begin{tabular}{|c|c|}
\hline \multicolumn{2}{|l|}{ Dados pessoais } \\
\hline Nome & Helena Akemi Wada Watanabe \\
\hline 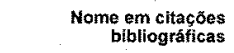 & WATANABE, H.A.W. \\
\hline Sexo & Feminino \\
\hline Endereço profissional & 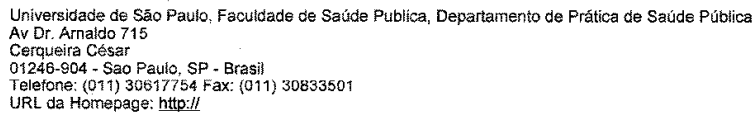 \\
\hline Endereço èletrônico & hwatanab Qusp.br \\
\hline
\end{tabular}

\begin{tabular}{|c|c|}
\hline \multicolumn{2}{|c|}{ Formação acadêmica/Titutaçăo } \\
\hline $1994-1999$ & 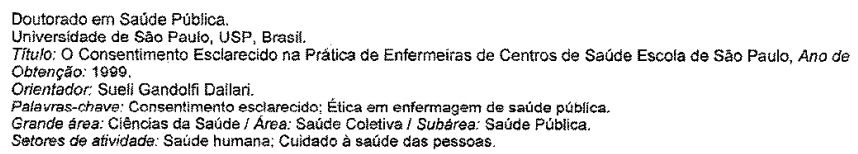 \\
\hline $1988-1993$ & 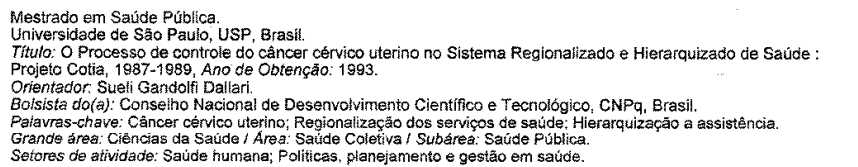 \\
\hline $1985-1985$ & 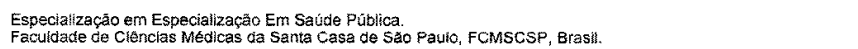 \\
\hline $1983-1983$ & Graduăçăo em Habilitaçâo Em Enfermagem de Saúde Pública. Universidade de Săo Paulo. USP, Brasil. \\
\hline $1980 \cdot 1983$ & Graduaçăo em Licenciatura Em Enfermagem. Universidade de Săo Paùlo, USP, Brasil. \\
\hline $1979-1982$ & Graduaçăo em Enfermagem, Universidade da Săo Paulo, USP, Brasil. \\
\hline $1976-1978$ & $\begin{array}{l}\text { Ensinio Médio (2० graus). } \\
\text { Colésio Bandeirantes, } \mathrm{CB} \text {, Brasil. }\end{array}$ \\
\hline $1972-1975$ & $\begin{array}{l}\text { Ensino Fundamental }\left(1^{0} \text { grau }\right) . \\
\text { Colégio Bandeirantes, } C B \text {, Brasil. }\end{array}$ \\
\hline
\end{tabular}

Formaçäo complementar

2001 - 2001 SCap Politica y Gestlón de Sistemas de Salud. (Carga horária: 8011). 


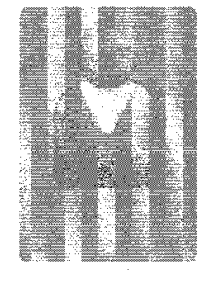

Mirela Bertoli Passador

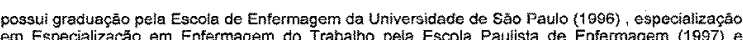

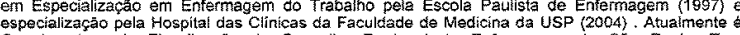

Coordenadora de Fiscaliząăa do Conselho Regional de Enfermagem de Sáo Paulto TTem

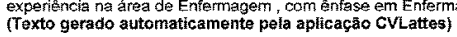

Uiltima atualização do curriculo em 25/108/2008

Endereço para acessar este CV:

Gerticicudo:

hitp: /lattes. cnpq.br/4763619332424738

\begin{tabular}{|c|c|}
\hline \multicolumn{2}{|l|}{ Dados pessoais } \\
\hline Nome & Mirela Bertoli Passador \\
\hline $\begin{array}{r}\text { Nome em citaçốes } \\
\text { bibliográficas }\end{array}$ & PASSADOR, M. B. \\
\hline Sexo & Feminino \\
\hline Endereço profissional & 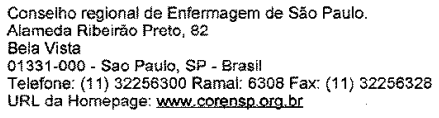 \\
\hline
\end{tabular}

\begin{tabular}{|c|c|}
\hline \multicolumn{2}{|l|}{ Formaģāo acadèmicartitulaçáo } \\
\hline $1997-1997$ & 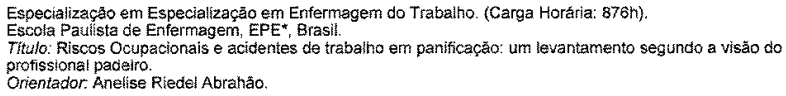 \\
\hline $1993-1996$ & 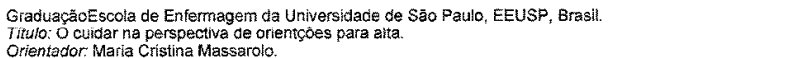 \\
\hline
\end{tabular}

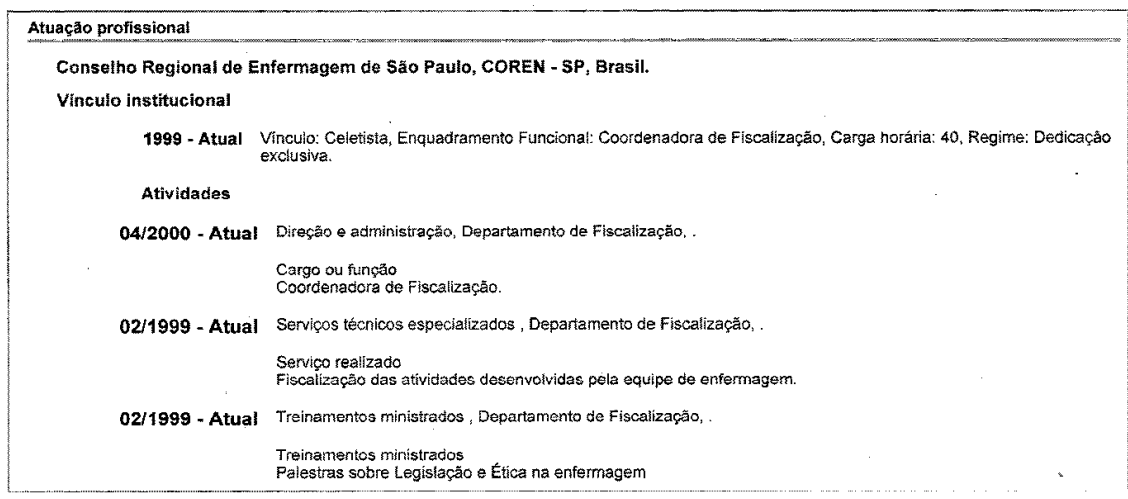

Areas de atuação

1. Grande área: Ciências dâ Saúde / Area: Enfermagem / Subarrea: Enfermagem Psiquiátrica

2. Grande área: Ciências da Saúde / Área: Enfermagem / Subárea: Enfermaşem de Saúde Pública.

Idiomas 